\title{
Inhibitors of the Endocannabinoid-Degrading Enzymes, or how to Increase Endocannabinoid's Activity by Preventing their Hydrolysis
}

\author{
Marion Feledziak $^{1,2}$, Didier M. Lambert ${ }^{2}$, Jacqueline Marchand-Brynaert ${ }^{1}$ and Giulio G. Muccioli ${ }^{3, *}$ \\ ${ }^{1}$ Université catholique de Louvain, Institute of Condensed Matter and Nanosciences, Laboratoire de Chimie Organique \\ et Médicinale, ${ }^{2}$ Université catholique de Louvain, Louvain Drug Research Institute, Medicinal Chemistry Research \\ Group, ${ }^{3}$ Université catholique de Louvain, Louvain Drug Research Institute, Bioanalysis and Pharmacology of \\ Bioactive Lipids Research Group
}

Received: August 29, 2011; Accepted: October 28, 2011; Revised: November 5, 2011

\begin{abstract}
Endocannabinoids are lipid transmitters binding and activating the cannabinoid receptors. Both cannabinoid receptors and endocannabinoids, such as 2-arachidonoylglycerol and anandamide, have been shown to control numerous physiological and pathological processes, including in the central nervous system. Thus regulating endocannabinoid levels in-vivo represents an interesting therapeutic perspective in several CNS-related diseases. To date four enzymes - Fatty Acid Amide Hydrolase (FAAH), N-Acylethanolamine-hydrolyzing Acid Amidase (NAAA), Monoacylglycerol Lipase (MAGL), $\alpha / \beta$-Hydrolase Domain 6 (ABHD6) - were shown to control endocannabinoid levels in tissues or in intact cells. While the searches for NAAA and ABHD6 inhibitors are still in their beginning, a growing number of selective and potent inhibitors are now available to inhibit FAAH and MAGL activities. Here, based on the literature and patent literature, we review the compounds of the different chemical families that have been developed to inhibit these enzymes, with a special emphasis on FAAH and MAGL inhibitors.
\end{abstract}

Keywords: Fatty acid amide hydrolase, FAAH, inhibitors, inflammation, monoacylglycerol lipase, MAGL, $N$ acylethanolamine-hydrolyzing acid amidase, palmitoylethanolamide, ABHD12, ABHD6.

\section{INTRODUCTION}

The effects of cannabinoids (from natural, synthetic and endogenous origin) are mainly mediated by two G proteincoupled receptors, the cannabinoid receptors $\mathrm{CB}_{1}$ and $\mathrm{CB}_{2}$. These two receptors are activated by endogenous bioactive lipids named endocannabinoids, which are produced in an activity-dependent manner (i.e. following cell stimulation) from phospholipid precursors present in the cell membranes. So far, two types of endocannabinoids, based on an arachidonic acid moiety, have been fully characterized. Indeed, $\mathrm{N}$ arachidonoylethanolamine (anandamide, AEA) is a member of the large family of $\mathrm{N}$-acylethanolamines, whereas 2arachidonoylglycerol (2-AG) is an acylglycerol. The activity of these lipid mediators at the cannabinoid receptors is terminated essentially following their hydrolysis by several lipases [1]. Initially, Fatty Acid Amide Hydrolase (FAAH) [2] and Monoacylglycerol Lipase (MAGL) [3, 4], were described as the main enzymes regulating the activity of AEA and 2-AG, respectively. More recently, additional endocannabinoid-degrading enzymes were also shown to have key roles in the endocannabinoid system. Thus, a second FAAHrelated mechanism was recently described for essentially regulating oleamide.[5] Although it shares only $20 \%$ homology with FAAH, this novel enzyme, only found in humans, was called FAAH-2. Two serine hydrolases,

*Address correspondence to this author at the Université catholique de Louvain, Louvain Drug Research Institute, Bioanalysis and Pharmacology of Bioactive Lipids Research Group, Avenue E. Mounier 72, B1.72.01, B1200 Bruxelles, Belgium; Tel: +32 276472 31; Fax: +32 276472 93;

E-mail: giulio.muccioli@uclouvain.be $\alpha / \beta$-hydrolase 6 (ABHD6) and $\alpha / \beta$-hydrolase 12 (ABHD12) [6], were also recently discovered and described as complementary 2-AG-degrading enzymes in the brain [7]. Interestingly, MAGL, ABHD6 and ABHD12 are present in different subcellular locations suggesting distinct roles in controlling 2-AG activities. In addition, another enzyme, called $N$ Acylethanolamine-hydrolyzing Acid Amidase (NAAA), was found to regulate the levels of $\mathrm{N}$-acylethanolamines [8].

Because the activation of the cannabinoid receptors results in multiple beneficial effects, numerous $\mathrm{CB}_{1}$ and $\mathrm{CB}_{2}$ agonists are being described since the characterization of $\Delta^{9}$ THC structure and of its activity at cannabinoid receptors. However direct and constant activation of the receptors resulting from this strategy presents several drawbacks, including receptor desensitization, and numerous CNS-related side effects for the $\mathrm{CB}_{1}$ receptor agonists. Conversely, increasing selectively the levels of an endocannabinoid is expected to result in a subset of the effects induced by the agonist but with more limited side effects [9]. Therefore there is a strong rationale for the preparation of potent and selective inhibitors of endocannabinoid degradation.

Thus, following a brief summary of the enzymes' characteristics, we will review the different classes of inhibitors described in the patent literature. The main focus will be on the compounds able to inhibit FAAH and MAGL since those are the primary enzymes controlling the endocannabinoid levels. However, we will also briefly describe the novel inhibitors developed to block the activity of NAAA. 


\section{FATTY ACID AMIDE HYDROLASE}

\section{II.1. Pharmacology of FAAH Inhibition or why Inhibit- ing FAAH Activity?}

FAAH is a membrane-bound serine hydrolase which belongs to a distinct class of enzymes characterized by the amidase signature (AS). It possesses an atypical catalytic triad consisting in Ser-Ser-Lys (instead of the classical SerHis-Asp) which confers to FAAH the ability to hydrolyse amide bonds of various endogenous bioactive lipids [10,11].

Essentially known for being the main anandamidedegrading enzyme [12], FAAH also hydrolyses and thus regulates the endogenous levels of other bioactive lipids (Fig. (1)). Indeed, several $N$-acylethanolamines (NAEs) including $N$-palmitoylethanolamine (PEA), which does not activate $\mathrm{CB}$ receptors but induces anti-inflammatory responses via the PPAR receptors, and the satiating agent $N$ oleoylethanol-amine (OEA) - also undergo a FAAHdependent catabolism $[13,14]$. Furthermore, the levels of other classes of amide-derived lipids, like the $N$-acyl taurines (NATs), which activate transient receptor potential (TRP) ions channels [15], and fatty acid primary amides (FAPAs) such as the sleep-inducing lipid oleamide [12, 16, 17], are also regulated by FAAH. Interestingly, while the levels of these mediators are increased upon FAAH inhibition the levels of two other bioactive lipids, $\mathrm{N}$-arachidonoyldopamine (a TRPV1 agonist) [18] and $\mathrm{N}$-arachidonoylglycine (the putative GPR18 receptor endogenous agonist) [19], are decreased following FAAH inhibition.

Considering all its different substrates, FAAH inhibition will result in numerous effects, with several of them not me- diated by anandamide or by cannabinoid receptors. These non-CB1 and non-CB2 effects can be mediated by G protein-coupled receptors (e.g. GPR18, GPR119), ion channels (e.g. TRPV1) or nuclear receptors (e.g. PPAR) [20, 21]. To date, only the consequences of increasing the levels of the $\mathrm{N}$ acylethanolamines are relatively well characterized both in cells and in-vivo. Anandamide was shown to be involved in number of physiological processes [22-25], including appetite regulation [26], pain [27, 28] and inflammation, but also various CNS and psychiatric disorders [29], with anxiety and depressive disorders being the most studied. Concerning other substrates, oleamide was shown to be involved in sleep induction [30, 31], PEA is widely described as analgesic and anti-inflammatory molecule $[27,28,32]$ and OEA as satiating factor and as analgesic [33]. OEA regulates feeding and body weight through activation of the nuclear receptor PPAR-alpha [34]. Today, FAAH inhibition is generally considered as a sound therapeutic strategy in the treatment of pain and inflammation [20,35-39] as well as anxiety and depression [40-42].

\section{II.2. FAAH, Structure and Function}

Soon after the discovery of FAAH, X-ray crystallographic studies were performed to further understand its mode of action, but also to improve the research and the development of its inhibitors. Thus the rat isoform $(r \mathrm{FAAH})$ was crystallised in presence of methylarachidonoylfluorophosphonate (MAFP), an irreversible and non selective inhibitor, and the structure was solved with a $2.8 \AA$ resolution [43], This three dimensional structure revealed the presence of several domains implicated in distinct functions. $i$ ) A large
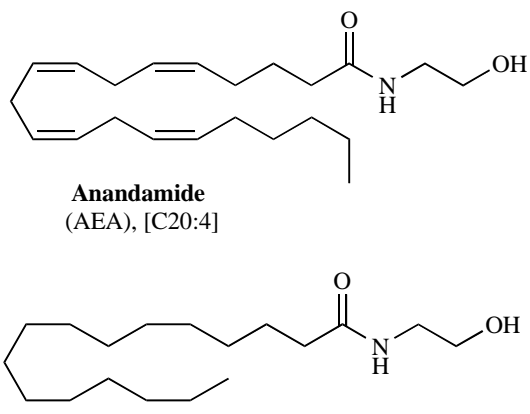

$N$-Palmitoyl ethanolamine (PEA), [C16:0]
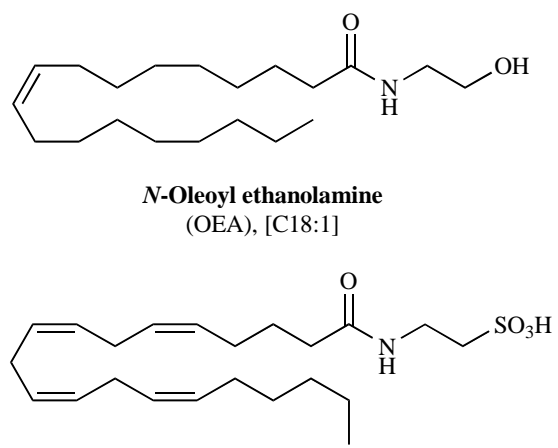

$\mathrm{N}$-Arachidonoyl taurine [C20:4]
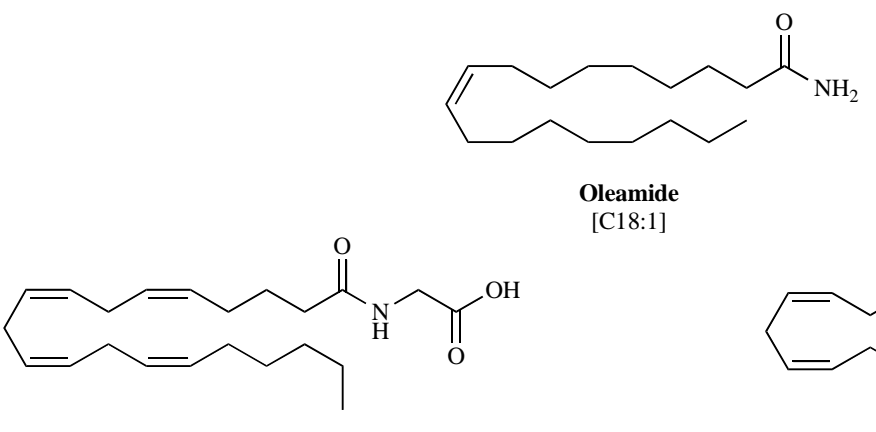

$\mathrm{N}$-Arachidonoyl glycine [C20:4]

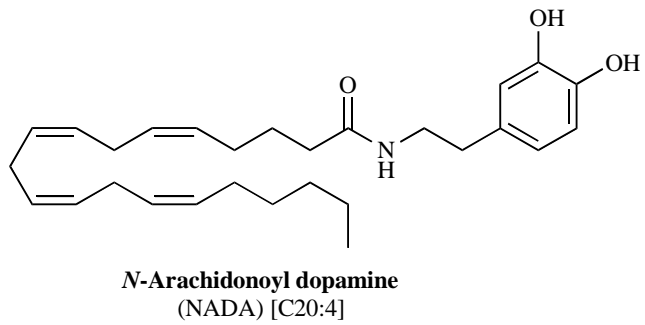

Fig. (1). Endogenous bioactive lipids regulated by FAAH. 
domain composed by hydrophobic and basic residues covers the active site and allows the enzyme to anchor to the membrane. ii) Near this hydrophobic plateau, lies a channel responsible for the entry of the substrate. Commonly called the membrane access channel (MAC), this cavity allows a direct access for the lipid substrate from the membrane to the active site. iii) Close to the active site, a hydrophobic cavity is present. This acyl-chain binding pocket (ABP) interacts with the side-chain of the substrate. $i v$ ) Finally, the cytosolic port (CP) was found to interact with the polar head of the substrate and is connected with the cytosol. Moreover, the active site is able to accommodate a water molecule to hydrolyse the acyl-enzyme complex. As a result, the hydrophobic moiety and the hydrophilic one are released towards the MAC and $\mathrm{CP}$, respectively. (For complete reviews, see [44, 45]) Further helping the drug development of FAAH inhibitors, an engineered "humanised" rat FAAH ( $h / r$ FAAH) [46] was produced and successively co-crystallised with three compounds representative of the major FAAH inhibitors classes [47-50]. This constitutes an interesting tool, as a large number of FAAH inhibitors present differences in activity depending on the origin of the enzyme, that is mouse FAAH (mFAAH) or human FAAH $(h \mathrm{FAAH})$. An alternative strategy was to develop an homology model of $h$ FAAH based on the reported X-ray structure of rat FAAH $(r \mathrm{FAAH})$ [51]. This model was validated by docking the selective inhibitor $\mathrm{PF}-750$ resulting in similar interactions to those found in the co-crystal structure of PF-750 into $h / r F A A H$.

A large number of FAAH inhibitors have been described over the years, starting from natural substrates analogues to well-adapted traditional types of serine hydrolase inhibitors [52-55]. Indeed, a wide variety of electrophilic functions has been used to target the enzyme's active site, generating large sets of structure-activity relationships aiming at improving, not only the potency, but also the selectivity of the inhibitors.
Among the numerous templates described in the patent literature (Fig. (2)), three main chemical families have been extensively studied. Below, we will review them in their order of development, starting from the $\alpha$-keto heterocycles [56], then the carbamate-based inhibitors [57] and finally, the urea-derived inhibitors [58].

\section{II.3. FAAH Inhibitors}

\section{II.3.1. a-keto Heterocycle-based FAAH Inhibitors}

Activated ketones were disclosed very early in the development of FAAH inhibitors. Disclosed for inhibiting serine proteases [59, 60], a first series was described by Dale Boger's group, who generated a series of arachidonoyl- and oleoyl-based $\alpha$-keto heterocycles [56]. The inhibition is based on the attack by FAAH's active serine on the electrophilic carbonyl of the inhibitor. The resulting reversible tetrahedral intermediate was recently observed in OL-135 $h / r$ FAAH co-crystals [48]. After studying a large range of heterocycles, $\alpha$-keto oxazoles and $\alpha$-keto oxazolopyridines were identified as the most efficacious moieties. Therefore, Boger's group refined its inhibitors and reported more potent heterocyclic inhibitors exemplified with OL-135 (Fig. (3), 1, $\mathrm{IC}_{50}=2.1 \mathrm{nM}$ and $>100 \mu \mathrm{M}$ on $m$ FAAH and on $m$ MAGL, respectively), a potent and highly selective pharmacological tool commonly used and based on the pyridyl oxazole template.

From this study, an optimal C6 linker length with a phenyl end-group was chosen to replace the fatty acid chain. Beside the acyl chain, the authors also explored the impact of the heterocycle nature. Thereby, analogues were synthesised, based on 2-keto-1,3,4-oxadiazole scaffold with a subnanomolar activity (2, Fig. (3), $\mathrm{K}_{\mathrm{i}}=290 \mathrm{pM}$ on $\left.r \mathrm{FAAH}\right)$ [61] and more recently, 2-keto-1,2,4-oxadiazole scaffold $\left(\mathbf{7}, \mathrm{K}_{\mathrm{i}}=\right.$ $920 \mathrm{pM}$ and $340 \mathrm{pM}$ on $h \mathrm{FAAH}$ and $r \mathrm{FAAH}$, respectively)

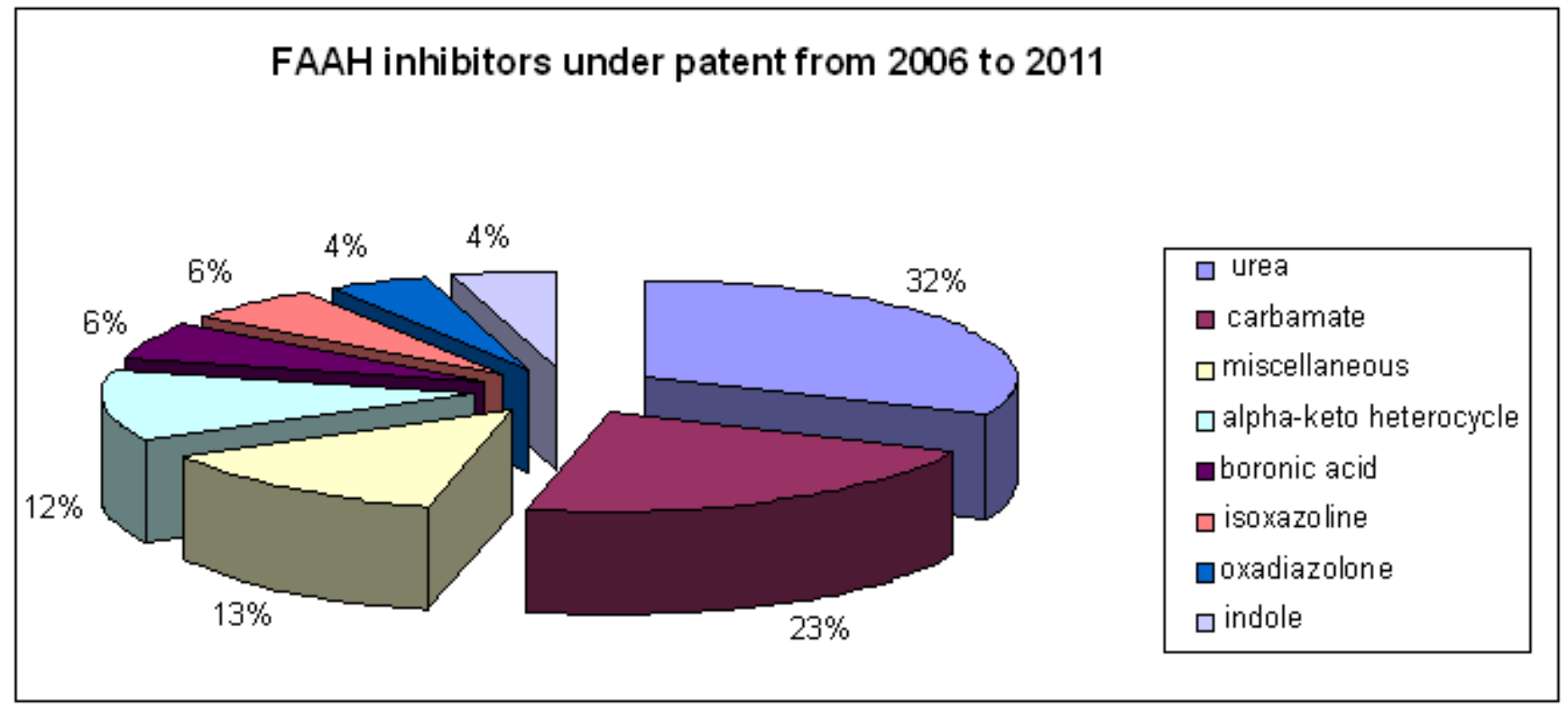

Fig. (2). Pie-chart, based on the chemical family, of the FAAH inhibitors families found in the patent literature (2006-2011). 
<smiles>O=C(CCCCCCc1ccccc1)c1ncc(-c2ccccn2)o1</smiles><smiles>O=C(O)c1ccc(-c2cnc(C(=O)CCCCCCc3ccccc3)o2)nc1</smiles>
WO2007098142

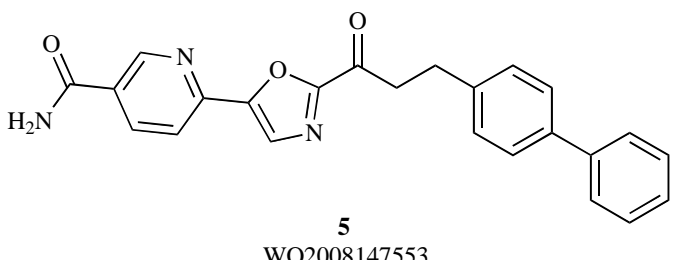

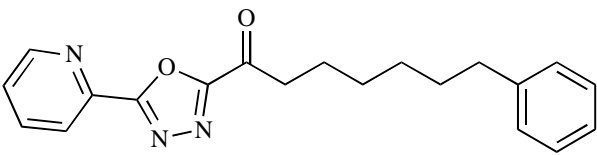

2

WO2006044617<smiles>N#Cc1cnc(C(=O)CCCCCCc2ccccc2)o1</smiles>

4

WO2008030532<smiles>O=C(CCCCCCc1cccc(Cl)c1)c1ncc(-c2ccccn2)o1</smiles>

6

WO2008150492

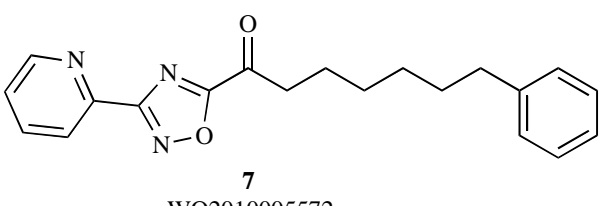

WO2010005572

Fig. (3). FAAH inhibitors based on $\alpha$-keto heterocycle templates described by Boger et al.

[62]. Similarly to the C6 alkylphenyl chain, the H-bond acceptor pyridine group appeared to be responsible for the higher potency. Boger's group also investigated the substitution of either the pyridine or oxazole ring [63, 64]. Again highly potent inhibitors were obtained featuring subnanomolar activities (Fig. (3), 3, $\mathrm{K}_{\mathrm{i}}=200 \mathrm{pM}$ and $2 \mathrm{nM}$ on $h$ FAAH and $r$ FAAH, respectively; $4, \mathrm{~K}_{\mathrm{i}}=900 \mathrm{pM}$ on $\left.h \mathrm{FAAH}\right)$. Focusing on the lipophilic portion that binds the ACB pocket, a series of bioisosteres was synthesized. For instance, equal activity to the C6 alkylphenyl chain was found for the $\mathrm{C} 2$ alkylbiphenyl chain, resulting in the inhibitor 5 (Fig. (3), $\mathrm{K}_{\mathrm{i}}$ $=400 \mathrm{pM}$ and $500 \mathrm{pM}$, on $h \mathrm{FAAH}$ and $r \mathrm{FAAH}$, respectively) [65]. Finally, the same authors also studied the substitution of the phenyl ring at the end of the acyl side-chain, resulting in inhibitors such as 6 (Fig. (3), $\mathrm{K}_{\mathrm{i}}=400 \mathrm{pM}$ on $r$ FAAH) [66].

Meanwhile, another study on $\alpha$-keto heterocycles was undertaken by the researchers of Janssen Pharmaceuticals. Based on the structure of OL-135 (1, Fig. (3)), including the oxazole ring, they oriented their efforts toward the insertion of a piperidinyl scaffold which allows for a wide diversity of substitutions. They published two patents containing SAR studies, and exemplified here with compounds 8 (Fig. (4), $400 \mathrm{pM}$ and $4.7 \mathrm{nM}$ on $h$ FAAH and $r$ FAAH, respectively) [67] and 9 (Fig. (4), $\mathrm{Ki}=2 \mathrm{nM}$ and $2 \mathrm{nM}$ on $h$ FAAH and $r$ FAAH, respectively) [68].

\section{II.3.2. Carbamate-based FAAH Inhibitors}

Carbamate-based FAAH inhibitors were inspired by the structures of previously reported inhibitors of serine hydro- lases. This function is usually used to inhibit serine proteases in an irreversible manner. Indeed, the tetrahedral intermediate evolves towards a stable acyl-enzyme complex. This mechanism of action was put forth, first by MS analyses [69] and then by X-ray structures [50], in studies involving URB597 (or KDS-4103, 10, Fig. (5)) the lead compound of this class of inhibitors [70, 71]. URB597 is largely used as pharmacological tool, both in-vitro and in-vivo $\left(\mathrm{IC}_{50}=4.6\right.$ $\mathrm{nM}$ on $r \mathrm{FAAH})$. In addition, analogues of $\mathbf{1 0}$ were synthesized in order to increase their stability towards oxidative metabolism. Indeed, hydroxylation of the $\mathrm{C} 4$ position was observed following in-vivo administration of 10. Thereby, this position was blocked by adding various substituents, like the gem-dimethyl found in 11 (Fig. (5)) [72], allowing a significant reduction of anandamide hydrolysis (50\% of control, at $30 \mathrm{nM})$.

Additional series of analogues were also synthesized, including compound 12 (Fig. (5), $\mathrm{IC}_{50}<0.1 \mu \mathrm{M}$ ) [73]. This compound is interesting as it exhibits a good oral bioavailability $\left(\mathrm{C}_{\max }\right.$ in plasma 2-fold higher compared to 10) and a low CNS uptake $\left(\mathrm{C}_{\max }\right.$ in brain 10 -fold lower compared to 10) which may thus allow to target selectively FAAH in the periphery while not affecting FAAH activity in the CNS. This feature may be useful to treat pain and inflammation disorders by acting at peripheral sites, without inducing potential CNS (side)effects. Another carbamate derivative, compound 13 (Fig. (5)), $\mathrm{IC}_{50}<0.1 \mu \mathrm{M}$ ) [74], also possesses a good oral bioavailability and its administration results in enhanced OEA and PEA levels in blood (7.55 and 8.85 $\mathrm{ng} / \mathrm{mL}$ compared to 4.18 and $4.17 \mathrm{ng} / \mathrm{mL}$ for OEA and PEA, 


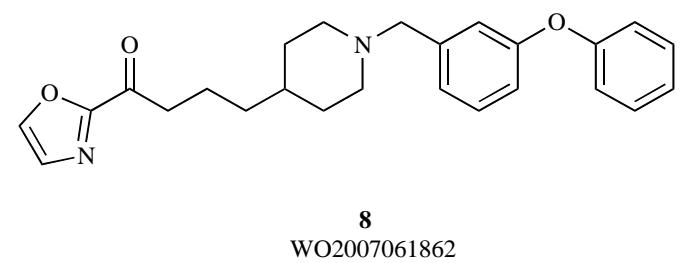

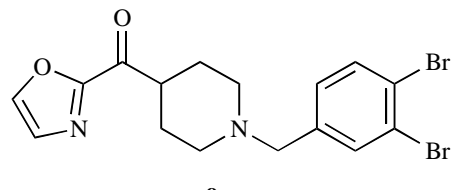

WO2007140005

Fig. (4). FAAH inhibitors based on $\alpha$-keto heterocycle templates described by Janssen Pharmaceutica.<smiles>NC(=O)c1cccc(-c2cccc(OC(=O)NC3CCCCC3)c2)c1</smiles>

10 (KDS-4103)

WO2004033422<smiles>O=C(NCC1CCCCC1)Oc1ccc(C(=O)O)cc1</smiles>

12

WO2008020866<smiles>CC1(C)CCC(NC(=O)Oc2cccc(-c3cccc(C(N)=O)c3)c2)CC1</smiles>

11

WO2008063714<smiles>CC(=O)Nc1ccc(OC(=O)NCC2CCCCC2)cc1</smiles>

13

WO2008021625<smiles>O=C(NC1CCCCC1)Oc1ccc(O)c(-c2ccccc2)c1</smiles>

14 (URB694)<smiles>Nc1ccc(OC(=O)NC2CCCCC2)cc1-c1ccccc1</smiles>

15<smiles>NC(=O)c1cccc(-c2cc(OC(=O)NC3CCCCC3)ccc2O)c1</smiles>

Fig. (5). Carbamate-type FAAH inhibitors developed by Piomelli et al. and Kadmus Pharmaceuticals.

respectively). The same authors described some other inhibitors but neither their potency nor in-vivo activity were disclosed [75, 76]. Piomelli and co-workers also developed new KDS-4103-based inhibitors with the aim to reduce its activity towards liver carboxylesterases. It is indeed known that 10 (URB597, Fig. (5)), while being quite selective, has several off-targets [77, 78], including carboxylesterases, which could prevent its further development. Thus, URB694 (14, Fig. (5), $\mathrm{IC}_{50}=30.0 \mathrm{nM}$ ) and the aniline analogue 15 (Fig. $\left.(\mathbf{5}), \mathrm{IC}_{50}=27.2 \mathrm{nM}\right)$ [79], both possessing electron-donating substituents on the phenyl ring that reduce the electrophilicity of the carbonyl, were described. This decreased electrophilicity resulted in more selective compounds that retained their good activity against FAAH in-vitro and in-vivo [80]. Therefore, novel URB694-based inhibitors could soon be developed with improved selectivity for FAAH. Note that recently, a first URB694 derivative, URB937, (16, Fig. (5), $\mathrm{IC}_{50}=26.8 \mathrm{nM}$ ) was disclosed to selectively inhibit FAAH in the periphery [81].

In addition, $O$-phenylcarbamates were also described by Astellas (17, Fig. (6), $\mathrm{IC}_{50}=12 \mathrm{nM}$ ) and Myllymaeki and coworkers (18, Fig. (6), $\mathrm{IC}_{50}=240$ pM, $r$ FAAH) [82, 83].
Due to their properties towards FAAH, carbamate-based inhibitors were also largely investigated by Sanofi-Aventis. Numerous series were described, based on various $O$ - and $N$ substituents including alkyl, piperazinyl, azetidinyl or thioazolyl, as illustrated in Fig. (7) [84-91]. These inhibitors were all described for having an analgesic activity and their inhibition potencies against $m$ FAAH are summarized in Fig. (8).

Two other carbamate-based families were developed at Sigma-Tau Pharmaceuticals: one is based on an enol carbamate template (27 and 28, Fig. (9), $\mathrm{IC}_{50}$ and $\mathrm{K}_{\mathrm{i}}$ both $<10 \mathrm{nM}$, $m$ FAAH) [92], and the other is based on an oxime carbamate (29, Fig. (9), $\mathrm{IC}_{50}$ and $\mathrm{K}_{\mathrm{i}}$ both $\left.<10 \mathrm{nM}, m \mathrm{FAAH}\right)$ [93]. These compounds are described as selective for FAAH over various cannabinoid-related targets $\left(<60 \%\right.$ versus $\mathrm{CB}_{1}, \mathrm{CB}_{2}$, TRPV1, NAPE-PLD, AMT, DAGL, MAGL, at a concentration equal to 1000 -fold their $\mathrm{IC}_{50}$ against FAAH).

Interestingly, 27-29 inhibit FAAH in a reversible manner which is quite unexpected for carbamate-type inhibitors. Invivo, compound $\mathbf{2 8}$ exhibits analgesic activity and reduces anxiety without affecting locomotor activity, whereas $\mathbf{2 9}$ was able to reduce anxiety as well as the hyperalgesia in a model of neuropathic pain. 
<smiles>O=C(O)c1cncc(OC(=O)N2CCC(CCCc3ccccc3Cl)CC2)c1</smiles>

WO2006088075<smiles>CCCCCCCCCCCCNC(=O)Oc1cccc(-c2csnn2)c1</smiles>

18

WO2008129129

Fig. (6). Carbamate-type FAAH inhibitors described by Astellas Pharma and Saario et al.<smiles>CCCCCCC(C)NC(=O)OCC(=O)NC</smiles>

$19\left(\mathrm{IC}_{50}=7 \mathrm{nM}\right)$ WO2006117461<smiles>NC(=O)c1cc(COC(=O)NCCC2CCN(c3ccc4cc(Cl)ccc4n3)CC2)on1</smiles>

$21\left(\mathrm{IC}_{50}=1 \mathrm{nM}\right)$ WO2010055267<smiles>O=C(NCC1CC2CN(c3ccc(-c4ccc(F)cc4)cn3)CC2C1)OCc1cscn1</smiles><smiles>CNC(=O)c1cc(COC(=O)N2CC3(CC(Oc4ccc(-c5ccc(F)cc5)cc4)C3)C2)on1</smiles><smiles>CNC(=O)c1cc(COC(=O)N2CC3CC(Oc4ccc(-c5ccc(F)cc5)cc4)CC3C2)on1</smiles><smiles>NC(=O)c1cc(COC(=O)NCC2CC3(CCN(c4ccc5cc(F)ccc5n4)CC3)C2)on1</smiles>

Fig. (7). Carbamate-type FAAH inhibitors described by Sanofi-Aventis.

\section{II.3.3. Urea-based FAAH Inhibitors}

Due to its high resistance towards chemical and biological hydrolysis, the urea function is usually not considered as a pharmacophore to inhibit serine hydrolases. However, it was shown that adding a good leaving group, such as an aniline function, transforms urea into a more reactive moiety, which could then function as enzyme inhibitor. Urea-based FAAH inhibitors originated from high-throughput screening studies of industrial chemical libraries. Both Janssen Pharmaceuticals and Takeda companies described compounds based on a piperazinyl urea moiety (30 and 31, Fig. (12)). Compound 30 exhibits an $\mathrm{IC}_{50}$ value of $16 \mathrm{nM}$ or $50 \mathrm{nM}$ depending on the source of enzyme (human and rat, respectively) [94], while for $31100 \%$ of enzyme ( $r$ FAAH) inhibition was obtained at $1 \mu \mathrm{M}$ [95].

However, the development of urea-based FAAH inhibitors really started with the discovery at Pfizer of PF-622 and PF-750 (32 and 33, Fig. (10), $\mathrm{k}_{\text {inact }} / \mathrm{K}_{i}=621 \mathrm{M}^{-1} . \mathrm{s}^{-1}$ and 791 $\mathrm{M}^{-1} . \mathrm{s}^{-1}$ on $h$ FAAH, respectively) $[46,58]$. 


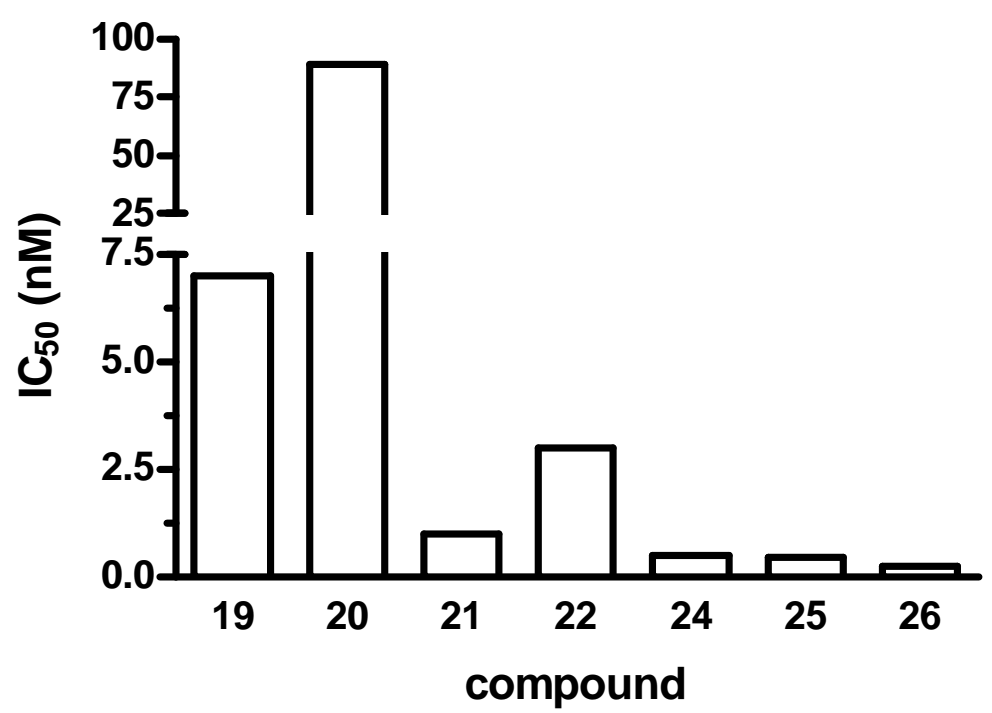

Fig. (8). IC $_{50}$ values of the carbamate-based inhibitors from Sanofi-Aventis depicted in Fig. (7).<smiles>C=C(OC(=O)N1CCCCC1)c1cccc(-c2cccc(OC(=O)N3CCCCC3)c2)c1</smiles>

27 (ST-4070) WO2009109504<smiles>C=C(OC(=O)N1CCCCC1)c1ccc(-c2ccccc2)cc1</smiles><smiles>C/C(=N\OC(=O)Nc1ccccc1)c1cccc(-c2cccs2)c1</smiles>

Fig. (9). Carbamate-type FAAH inhibitors described by Sigma-Tau Pharmaceuticals.<smiles>O=C(Nc1ccccc1)N1CCN(Cc2ccc3ccccc3n2)CC1</smiles>

32
PF-622<smiles>O=C(Nc1ccccc1)N1CCC(Cc2cnc3ccccc3c2)CC1</smiles>

33
PF-750<smiles>O=C(Nc1cccnc1)N1CCC(Cc2cccc(Oc3ccc(C(F)(F)F)cn3)c2)CC1</smiles>

34
PF- 3845<smiles>O=C(Nc1cccnn1)N1CCC(=Cc2cccc(Oc3ccc(C(F)(F)F)cn3)c2)CC1</smiles>
35
PF-04457845<smiles>O=C(Nc1cccnn1)N1CCC(=Cc2cccc(Oc3ccc(Br)cn3)c2)CC1</smiles>

$\stackrel{36}{36}$ WO2008047229

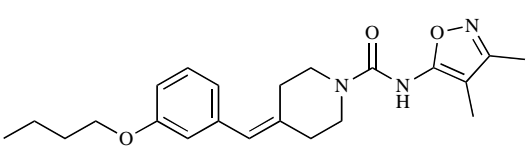

W02009127943<smiles>Cc1cccc(OCCOc2cccc(C=C3CCN(C(=O)Nc4cccnn4)CC3)c2)c1</smiles><smiles>Cn1nnnc1NC(=O)N1CCC2(CC1)CC(c1cccc(Oc3ccc(C(F)(F)F)cn3)c1)C2</smiles>

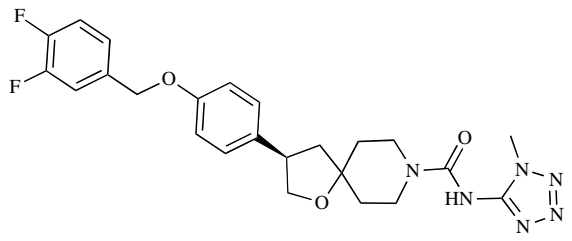

$\mathbf{4 2}$
WO2010058318

Fig. (10). Evolution of Pfizer's piperidinyl urea-type FAAH inhibitors. 
Indeed, after a high-throughput screening study to improve either drug-like pharmacokinetic properties and/or selectivity, Pfizer published a new kind of mechanistic class of inhibitors, based on the piperidinyl urea scaffold, showing a combination of potency and excellent selectivity [58]. Of note, the development of this class of inhibitors at Pfizer beneficiated from a $h / r$ FAAH three dimensional structure [46]. Thus, the stable acyl-enzyme complex was identified by MALDI-MS analyses and then by X-ray structures with $h / r$ FAAH, which confirmed the addition of the inhibitor to the active serine and the irreversible mechanism of inhibition. These studies led to a new chemical family obtained by replacing, not only the quinoline group of $\mathbf{3 2}$ and $\mathbf{3 3}$ with a biaryl ether group, but also the aniline leaving group with a 3 -aminopyridine one. These changes resulted in the inhibitor PF-3845 (34, Fig. (10)) which possesses much higher activity $\left(\mathrm{k}_{\text {inac }} / \mathrm{K}_{i}=14,310 \mathrm{M}^{1} \cdot \mathrm{s}^{-1}\right)$ [47]. Pfizer further described in several patents the synthesis and pharmacological evaluations of numerous urea-based inhibitors (e.g. compounds 3540, Fig. (10)) [96-100]. One line of research was to design more rigid compounds using a methylenepiperidine scaffold while incorporating a polar moiety to improve the pharmacokinetic parameters. This led to the clinical candidate PF04457845 (35, Fig. (10), $\mathrm{k}_{\text {inac }} / \mathrm{K}_{i}=40,300 \mathrm{M}^{-1} \cdot \mathrm{s}^{-1}$ ) which contains a pyridazinyl moiety instead of the 3 -aminopyridine one. This inhibitor exhibits a high selectivity for FAAH, excellent potency and good pharmacokinetic profile. The same company also prepared a new series of rigid piperidines where the methylene group was replaced with a $\mathrm{C} 4$ spirocycle (41 and 42, Fig. (10)) [101, 102]. The later inhibitors possess, similarly to the inhibitors containing a methylene unit, a high potency against FAAH activity.

It is difficult to directly compare the inhibitory activity of Pfizer's ureas with the other types of inhibitors since their potency is expressed in the literature as $\mathrm{k}_{\text {inac }} / \mathrm{K}_{i}$ values instead of the $\mathrm{IC}_{50}$ values traditionally reported. However, the use of $\mathrm{k}_{\text {inac }} / \mathrm{K}_{i}$ values appears more suitable than $\mathrm{IC}_{50}$ values when studying irreversible inhibitors. Note that in the same assay, the well-known URB597 (10, KDS-4103, Fig. (5)) shows a $\mathrm{k}_{\text {inac }} / \mathrm{K}_{i}$ value of $1,590 \mathrm{M}^{-1} . \mathrm{s}^{-1}$ Fig. (11). Based on all the reported assays, piperidinyl ureas appeared to be more selective and efficacious than KDS-4103 [47].

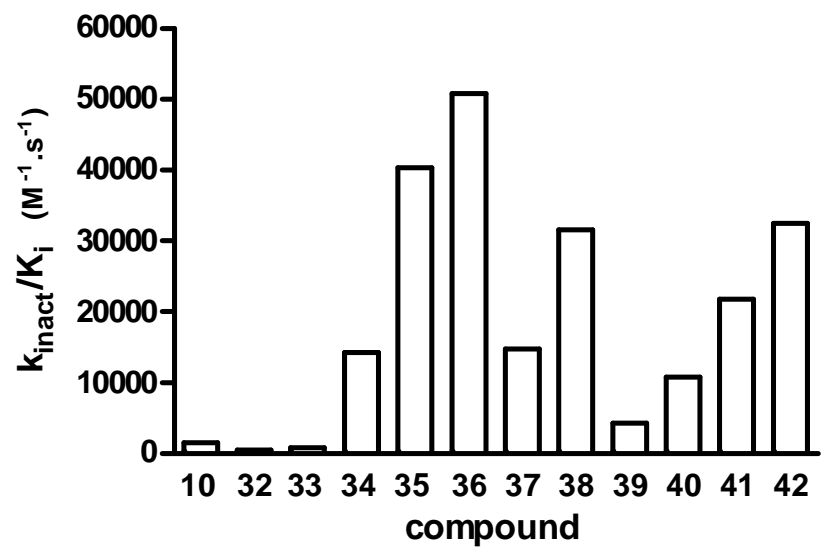

Fig. (11). Potency of Pfizer's ureas compared to the carbamatebased inhibitor KDS-4103 (10, Fig. (5)).

Note that a highly potent inhibitor is characterized by a high $\mathrm{k}_{\text {inact }} / \mathrm{K}_{\mathrm{i}}$ value (and a low $\mathrm{IC}_{50}$ value).
While other urea-derivatives have been investigated by several pharmaceutical companies, piperazinyl urea remains the most common template. $i$ ) Sanofi-Aventis described two compounds exhibiting dual inhibition against both $m$ FAAH and $m$ MAGL (43 and 44, Fig. (12)) [103, 104]. ii) Janssen Pharmaceuticals reported two additional series of compounds (45-49, Fig. (12) and 53, Fig. (13)). Compound 46 (Fig. (12), $\mathrm{IC}_{50}=19 \mathrm{nM}$ and $6 \mathrm{nM}$ on $h$ FAAH and $r$ FAAH) [105] is derived directly from JNJ-1661010 (45, Fig (12)) structure, whereas compounds $\mathbf{4 7 - 4 9}$ [106] contained a biaryl ether motif. When administered in-vivo, 47 (Fig. (12), $\mathrm{IC}_{50}=$ $8 \mathrm{nM}$ and $10 \mathrm{nM}$ on $h$ FAAH and $r$ FAAH, $20 \mathrm{mg} / \mathrm{kg}$, po) showed analgesic effects in a model of mechanical allodynia. Its activity was improved by replacing the benzisoxazole moiety with an isoxazolopyridine resulting in compound $\mathbf{4 8}$ described as a subnanomolar inhibitor [107]. Inspired from the structure of 48,49 (Fig. (12), $\mathrm{IC}_{50}=1 \mathrm{nM}$ ) conserves a biaryl ether moiety, but a pyridine replaces the isoxazolopyridine motif [108]. iii) Other piperazinyl urea-based FAAH inhibitors were shown to possess in-vivo efficacy. For instance, Astella published a series of inhibitors, illustrated with 50 (Fig. (12), $\mathrm{IC}_{50}=160 \mathrm{pM}, r \mathrm{FAAH}$ ), which seem to be useful in the context of overactive bladder [109], and Takeda published two families of compounds based on an isoxazole or pyridine moiety, exemplified here with $\mathbf{5 1}$, which exhibited analgesic effect at $10 \mathrm{mg} / \mathrm{kg}$ [110], and 52, which was proposed to treat sleep disorders [111]. iv) More recently, azetidinyl ureas were described as FAAH inhibitors. Vernalis described compound 53 Fig. (13) which exhibits an $\mathrm{IC}_{50}$ value of $3 \mathrm{nM}$ on $h$ FAAH [112]. Janssen Pharmaceuticals investigated also azetidinyl ureas with compound $\mathbf{5 4}$ Fig. (13), which presents an $\mathrm{IC}_{50}$ value of $1 \mathrm{nM}$ both on $h$ FAAH and $r$ FAAH [113], and the recently published rigid spirocyclic compound 55 (Fig. (13), $10 \mathrm{nM}$ and $20 \mathrm{nM}$ on $h$ FAAH and $r$ FAAH, respectively) [114].

\section{II.3.4. Boronic acid-based FAAH Inhibitors}

Recently, a new kind of FAAH inhibitors using a boronic acid as the electrophilic function was reported. This function has been already described for inhibiting serine proteases in a reversible manner [115]. Indeed, boron's ability to go up from a trigonal planar geometry to a tetrahedral geometry allows boronic acids to form a transient and reversible tetrahedral intermediate with the nucleophilic serine. Both Infinity Pharmaceuticals (56, Fig. (14)) [116] and Minkkila and co-workers (57, Fig. (14)) [117] published in 2008, the first arylboronic acids described as FAAH inhibitors. These two inhibitors exhibited nanomolar activities $\left(\mathrm{K}_{\mathrm{i}} \leq 10 \mathrm{nM}\right.$ for $\mathbf{5 6}$ and $\mathrm{IC}_{50}=9.1 \mathrm{nM}$ for 57) and a reversible inhibition of the enzyme. In the case of compound 56, kinetic data consolidated the hypothesis of a reversible inhibition. Furthermore, supplementary investigations were undertaken to unravel the interactions between the inhibitor and the enzyme. Both the molecular modelling studies and mutagenesis studies of $r$ FAAH demonstrated that the phenyl moiety of these inhibitors interacts with the enzyme's hydrophobic channel.

Infinity Pharmaceuticals further covered this area with three patents in 2009 and 2010. Thus, they developed several series of FAAH inhibitors based on various substituted arylboronic acids, exemplified with compounds 58 [118] and 59 [119] (Fig. (14), $K_{i} \leq 10 \mathrm{nM}$ ), and also based on a tetrahydro 


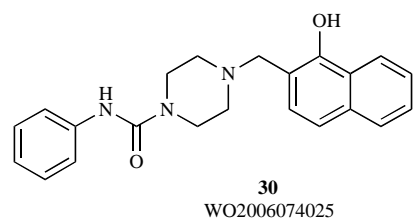<smiles>O=C(Nc1cccnc1)N1CCN(c2nc(-c3ccccc3)ns2)CC1</smiles>
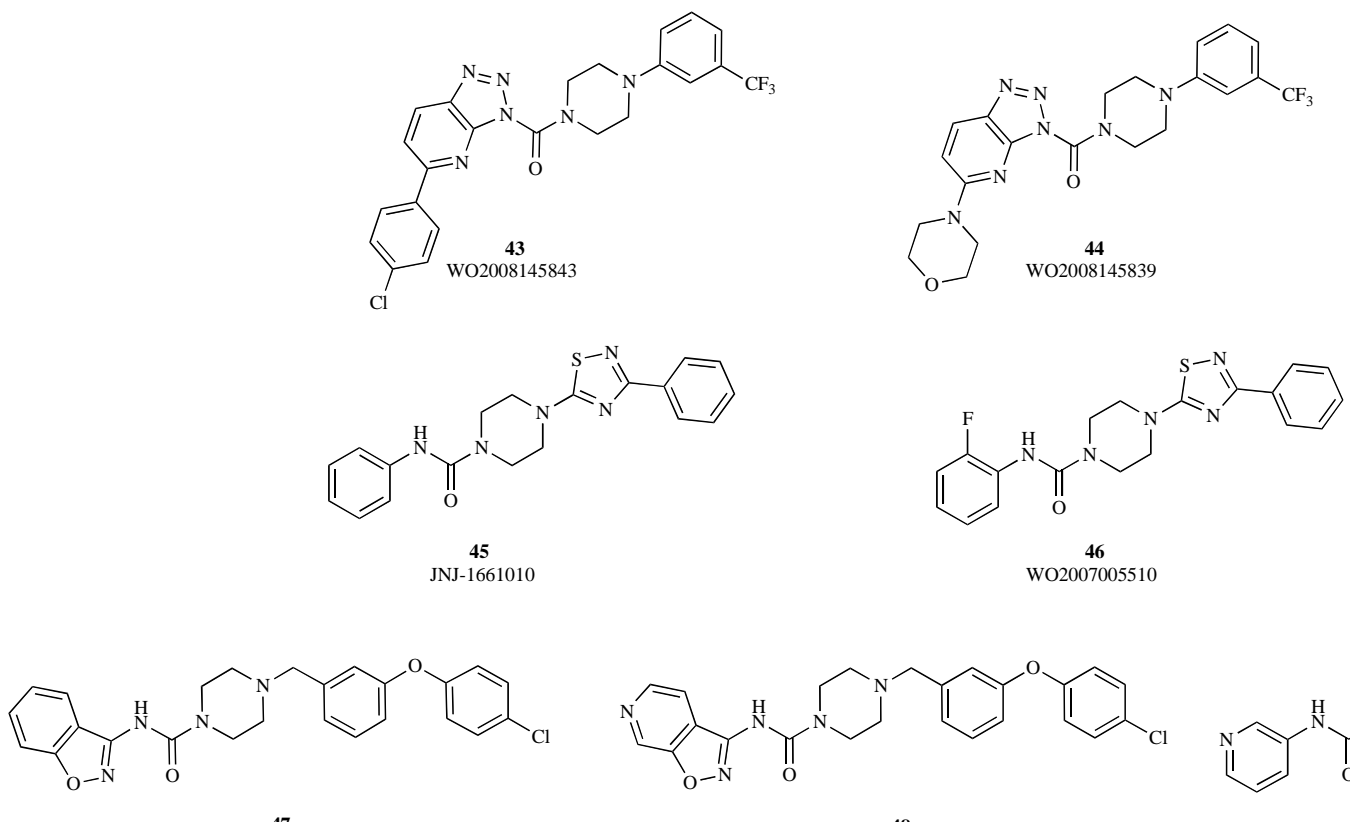

$$
\begin{gathered}
\mathbf{4 7} \\
\text { WO2008153752 }
\end{gathered}
$$
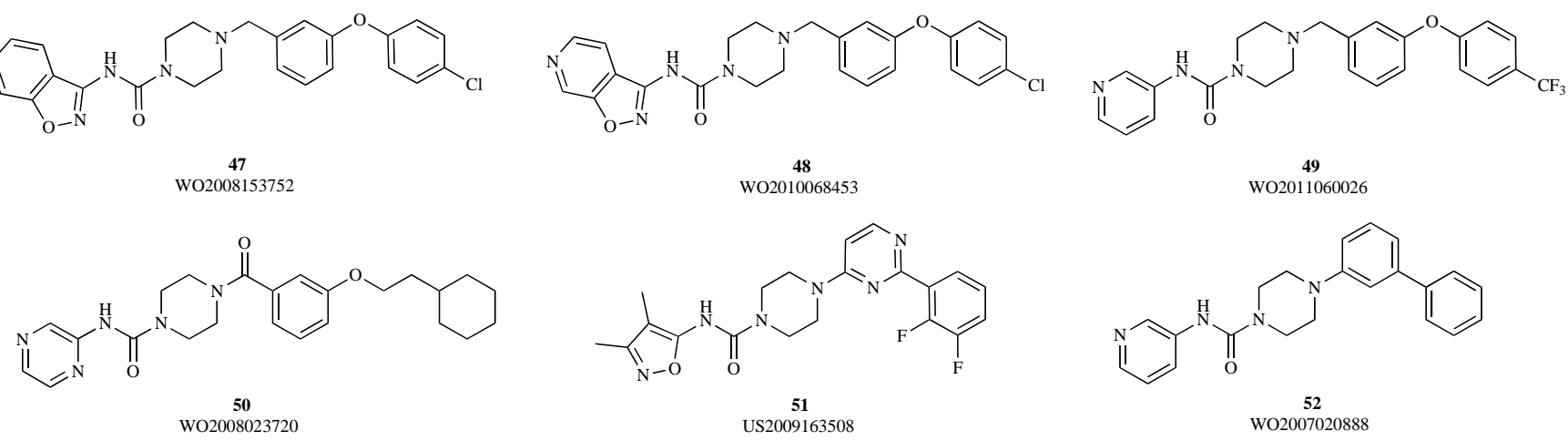
$\stackrel{49}{\text { WO2011060026 }}$

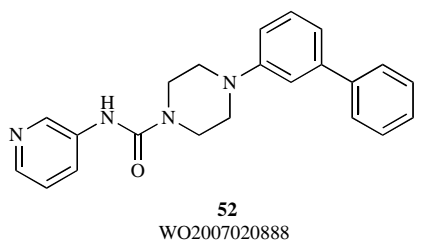

Fig. (12). Urea-type FAAH inhibitors.<smiles>O=C(Nc1cccnn1)N1CC(Oc2ccc(-c3cccc(OCCOCc4ccccc4)c3)cn2)C1</smiles>
$\stackrel{53}{\text { WO2009109743 }}$<smiles>O=C(Nc1cnccc1Cl)N1CC(CCOc2cccc(Oc3ccc(Cl)cc3)c2)C1</smiles>

$\stackrel{54}{\text { WO2010141809 }}$<smiles>O=C(Nc1ccc(-n2nccn2)nc1)N1CCC2(CC1)CN(Cc1cccc(Oc3ccc(Cl)cc3)c1)C2</smiles>

Fig. (13). Urea-type FAAH inhibitors from Vernalis and Janssen Pharmaceuticals. 

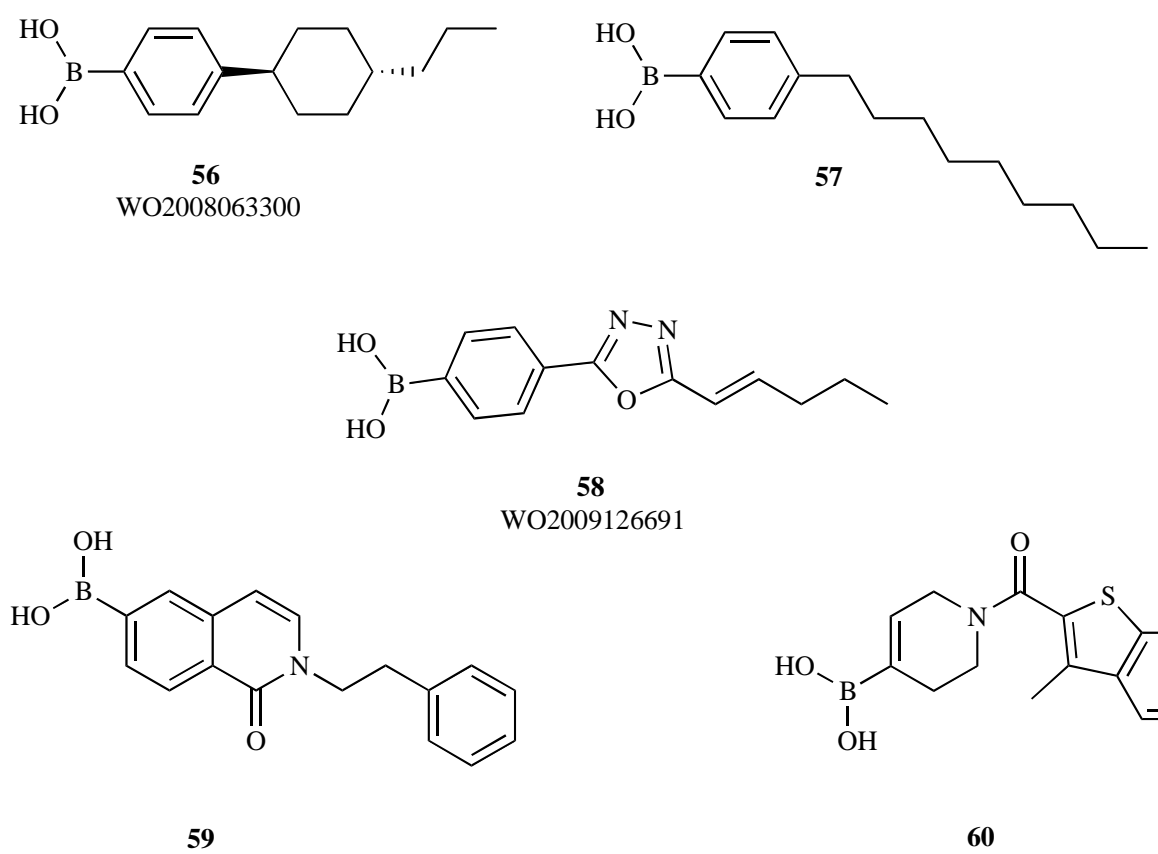

58

WO2010118155<smiles>Cc1c(C(=O)N2CC=C(B(O)O)CC2)sc2ccccc12</smiles>

60

WO2010118159

Fig. (14). Boronic acids developed as FAAH inhibitors.

pyridine boronic acid (i.e compound 60, Fig. (14), $\mathrm{K}_{\mathrm{i}} \leq 10$ nM) [120].

\section{II.3.5. FAAH Inhibitors of Miscellaneous Structures}

Whereas initially, carbamate and activated ketone-based inhibitors were mainly described, a wider diversity of templates has been explored since 2006. Some indole and pyrrole derivatives were investigated by Ironwood Pharmaceuticals (Microbia) which published several patents from 2006 to 2011 [121-125]. Therein, different series of compounds were disclosed that were, not only FAAH inhibitors, but that also interact with one or several targets involved in inflammation and pain (e.g. COX-1 or COX-2). For example, compounds 61 [122], 62 [123] and 63 [125] (Fig. (15)) were found to inhibit $h \mathrm{FAAH}$ at submicromolar concentrations.

Bial (Portela \& $\mathrm{C}^{\mathrm{o}}$ ) reported several series of oxadiazolones (64, 65 and 66, Fig. (16)) as FAAH inhibitors being selective for peripheral over CNS located FAAH [126-128].

Indeed, following administration of the inhibitors to mice ( $30 \mathrm{mg} / \mathrm{kg}$, p.o.) the residual activity in liver was found to be very low $(5 \%, 6 \%$ and $29 \%$ compared to the control, for 64, 65 and 66 respectively) whereas it was almost completely conserved in brain $(83 \%, 86 \%$ and $84 \%$ compared to the control, for 64,65 and 66 respectively).

Merck designed various heterocycle-based FAAH inhibitors like imidazole, pyrazole or oxazole cycles. Thus, two series of imidazole derivatives were described which inhibit $h$ FAAH with nanomolar and subnanomolar activities (Fig. (17), compounds 67 and 68, $\mathrm{IC}_{50}$ values of $6.3 \mathrm{nM}$ and 0.2 $\mathrm{nM}$, respectively) $[129,130]$. In addition, a pyrazole series was published, illustrated with 69 (Fig. (17), $\mathrm{IC}_{50}$ value of $0.47 \mathrm{nM}$ ) [131] and also an oxazole one, represented by 70 Fig. (17) [132]. The inventors described the later inhibitor as having good cell permeability $\left(\mathrm{IC}_{50}=5\right.$ and $20 \mathrm{nM}$, in cell lysate and in whole cell, respectively).

Renovis published several lipophilic and polycyclic compounds as FAAH modulators. For instance, compounds 71 [133] and 72 [134] exhibited nanomolar $\mathrm{IC}_{50}$ values (Fig. (18), $\mathrm{IC}_{50}<100 \mathrm{nM}$ and $\mathrm{IC}_{50}=1.2 \mathrm{nM}$ for 71 and 72, respectively) while compound 73 (Fig. (18)) [135] showed more than $75 \%$ of FAAH inhibition at $1 \mu \mathrm{M}$ compared to the control.

Janssen Pharmaceuticals developed also a family of inhibitors based on a pyrimidine moiety with a C6 aryl group and a C4 amine function. Compounds 74 [136] and 75 Fig. (19) [137] featured nanomolar activities (Fig. (19), $\mathrm{IC}_{50}=1$ and $3 \mathrm{nM}$ for 74 and $\mathrm{IC}_{50}=7$ and $240 \mathrm{nM}$ for 75, against $h$ FAAH and $r$ FAAH, respectively).

Very recently, Infinity Pharmaceuticals identified the isoxazoline heterocycle as a new template for FAAH inhibition. Four series of compounds were presented based on this new scaffold. The representative compounds 76, 77, 78 and 79 (Fig. (20)) were reported to have $K_{i} \leq 100 \mathrm{nM}$ and an irreversible mode of $h$ FAAH inhibition [138-140]. Indeed, the authors reported evidence for a covalent FAAH inhibition via kinetic data, on one hand, and rapid dilution experiments, on the other hand, confirming the irreversible or slowly reversible inhibition. This mechanism of action was explained by the nucleophilic addition of the active Ser-241 on the isoxazoline $\mathrm{C}=\mathrm{N}$ function followed by the elimination of the leaving group, i.e. $\mathrm{Br}$ or ArO substituent at C3.

\section{II.3.6 Other Structures Not Covered by Patents}

Since 2006, a number of inhibitors have been published in the literature but are not covered by patents. We have summarized here the main families. A family of 2-thioxo- 
<smiles>Cc1c(C(=O)C(=O)Nc2ccncc2)c2ccccc2n1Cc1ccc(Cl)cc1</smiles>

61

WO2008157740

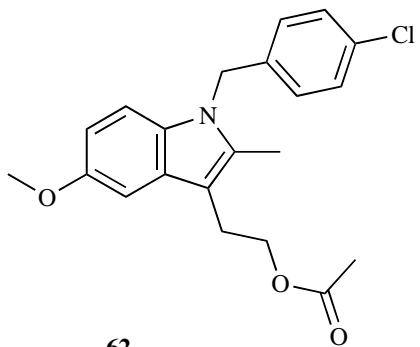

WO2007022501

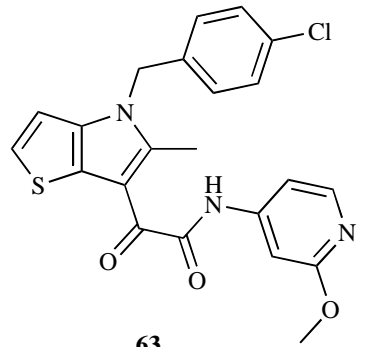

WO2011071996

Fig. (15). 2-Methylindole-based inhibitors of FAAH.
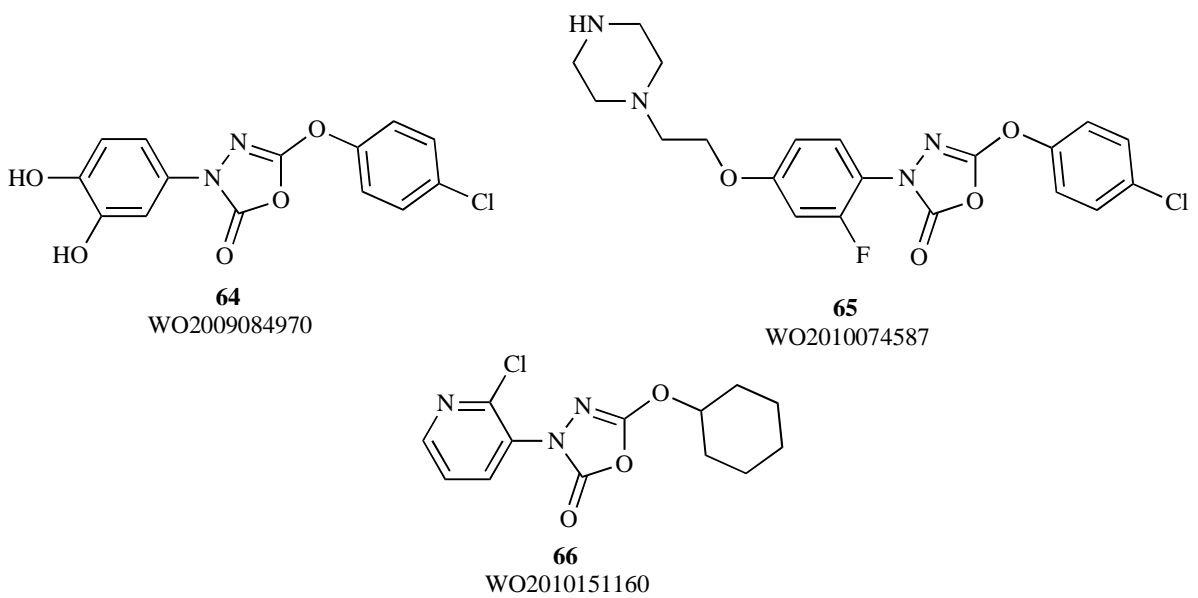

Fig. (16). Oxadiazolone-type FAAH inhibitors.
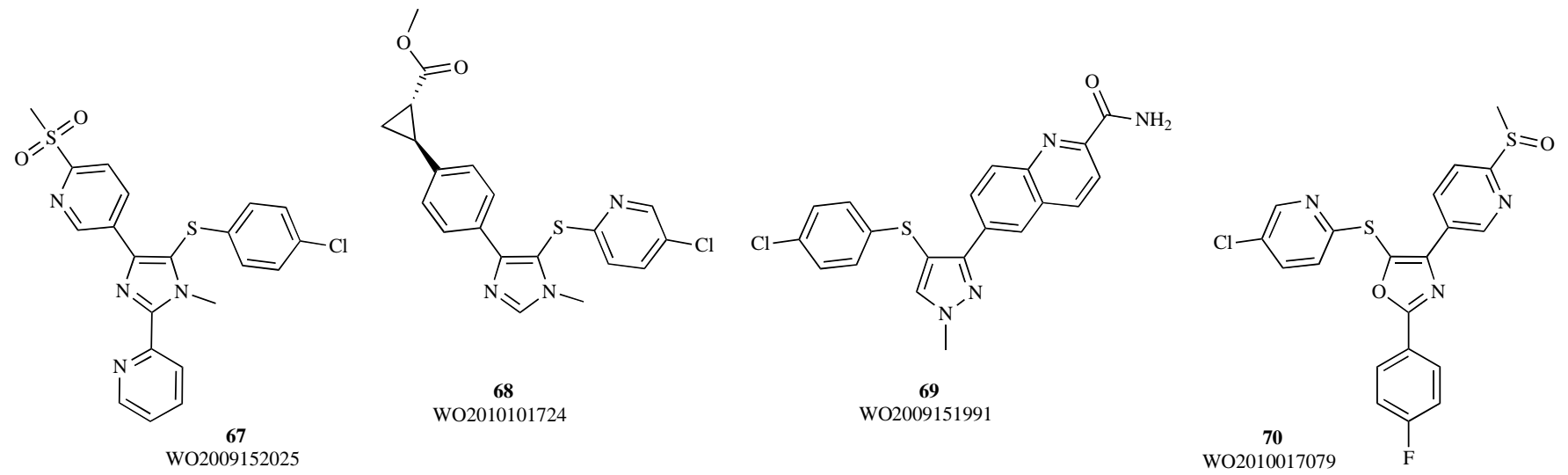

Fig. (17). Central heterocyle-based FAAH inhibitors from Merck.

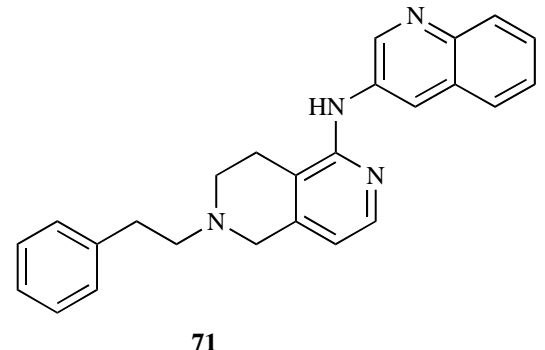

WO2009011904

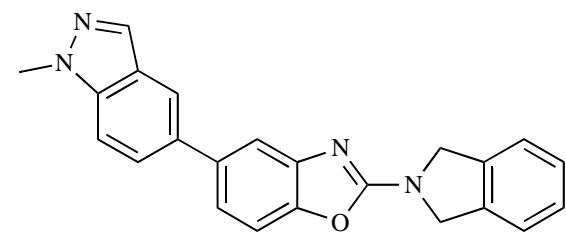

72 WO2010039186<smiles>c1ccc2ncc(Nc3ncnc4c3CN(Cc3cccc5cc[nH]c35)C4)cc2c1</smiles>

WO2010059610

Fig. (18). FAAH inhibitors from Renovis. 


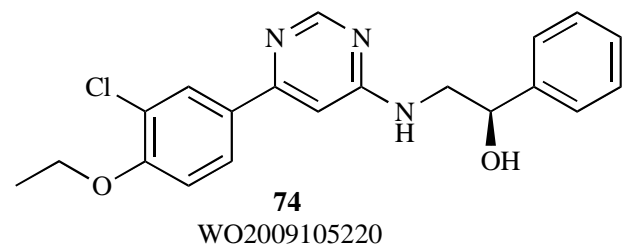<smiles>CCSc1ccc(-c2cc(NC[C@H](N)c3ccccc3)ncn2)cc1</smiles>

Fig. (19). Pyrimidine-based FAAH inhibitors from Janssen Pharmaceuticals.

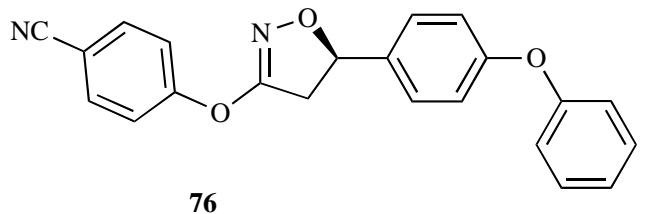

WO2010135360

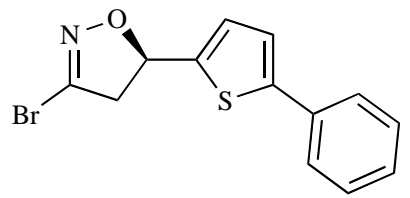

78

US2011028482

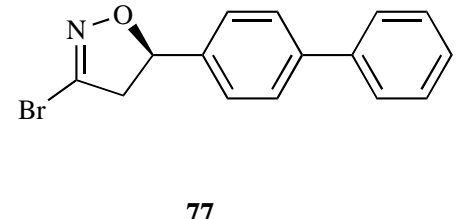

US2011028478

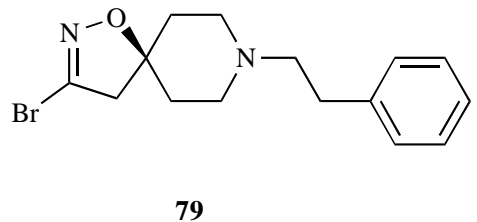

US2011034437

Fig. (20). Isoxazoline-based FAAH inhibitors described by Infinity Pharmaceuticals.

imidazolidin-4-ones was described to inhibit FAAH in a reversible and competitive manner (80, Fig. (21), $\left.\mathrm{pI}_{50}=5.86\right)$ [141]. Then, benzothiazole-based inhibitors were reported to reversibly inhibit FAAH with nanomolar activity $(\mathbf{8 1}$, Fig. (21), $\mathrm{IC}_{50}=1.7 \mathrm{nM}$ ) [142]. During the same year, two distinct series of paracetamol [143] and ibuprofen [144] analogues were disclosed to block FAAH activity with good to moderate potency $\left(\mathbf{8 2}\right.$ and $\mathbf{8 3}$, Fig. (21), $\mathrm{IC}_{50}=100 \mathrm{nM}$ and $\mathrm{pI}_{50}=5.86$, respectively). A unique series of 1-indol-1-ylpropan-2-ones was also described for a dual inhibition towards FAAH and cytosolic phospholipase $\mathrm{A}_{2} \alpha(\mathbf{8 4}$, Fig. (21), $\mathrm{IC}_{50}=47 \mathrm{nM}$ and $2.2 \mu \mathrm{M}$ against FAAH and $\mathrm{cPLA}_{2} \alpha$, respectively) [145]. In 2009, $\beta$-lactam-based inhibitors were disclosed to inhibit FAAH in a reversible manner without being processed by the nucleophilic serine (85, Fig. (21), $\left.\mathrm{IC}_{50}=8 \mathrm{nM}\right)[51,146]$. Additionally, the first potent noncovalent and competitive inhibitors of FAAH were disclosed (86, Fig. (21), $\left.\mathrm{IC}_{50}=36 \mathrm{nM}\right)$ [147].

\section{II.4. Current Clinical Trials Involving FAAH Inhibitors}

Based on the preclinical studies reported so far, the most promising therapeutic applications for FAAH inhibitors are to be found in the treatment of pain and mood, and sleep disorders. Recently, Pfizer undertook a phase II clinical trial with PF-04457845 (35, Fig. (10)) to evaluate its efficacy, safety and tolerability in knee osteoarthritis (NCT00981357). Another small scale clinical trial (NCT01092845) aimed at studying the effect of $\mathbf{3 5}$ on sleep. Indeed, a positive effect on sleep would represent a proof-of-concept for the CNS efficacy of the compound, and more largely of increasing AEA levels, in humans.
In addition, phase II clinical trials were also undertaken to evaluate SSR-411298, a FAAH inhibitor developed by Sanofi-Aventis, for treatment of major depressive disorders in the elderly patients (NCT00822744). To date, neither the inhibitor structure nor results were reported concerning these investigations. Note however that although the development of SSR-411298 in this indication has been abandoned, other indications (e.g. pain, NCT01439919) are being investigated.

Infinity Pharmaceuticals is developing IPI-940 (no structure available) in order to treat various types of pain. Phase I resulted in positive data, and IPI-940 is presented as a welltolerated compound with good pharmacokinetic, pharmacodynamic and safety properties. Purdue Pharmaceutical Products is expected to initiate Phase II studies with this compound. Finally, Vernalis has its own FAAH inhibitor, V158866 $\left(\mathrm{IC}_{50}=24 \mathrm{nM}\right)$ entering Phase I clinical trials.

We are at the early stages of the clinical development of FAAH inhibitors; the results of the first Phase II trials are eagerly awaited to determine whether FAAH inhibition will prove to be a viable drug target.

\section{MONOACYLGLYCEROL LIPASE}

\section{1. MAGL, Structure and Mechanism of Action}

Although the existence of a monoacylglyceride hydrolase in the adipose tissues was reported decades ago [148, 149], MAGL became more actively investigated after its role in controlling 2-AG (Fig. (22)) levels was demonstrated [3-4].

Molecular cloning allowed determining the catalytic triad of the enzyme and its classification as a member of the $\alpha / \beta$ 

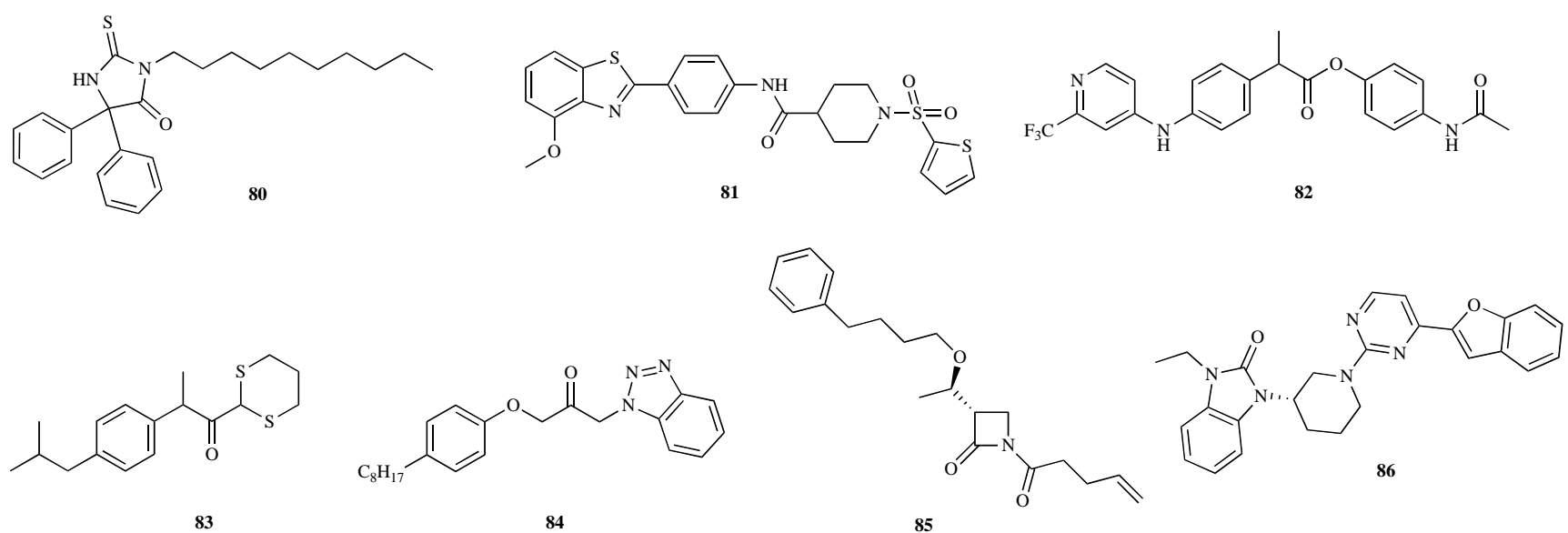

Fig. (21). FAAH inhibitors not covered by the patents.
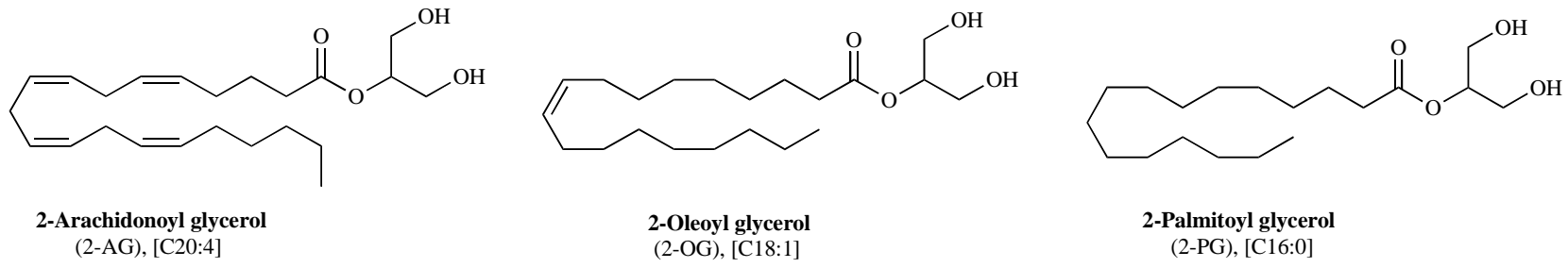

Fig. (22). Known endogenous substrates of MAGL.

hydrolase family [150], MAGL activity is governed by the classical Ser-His-Asp catalytic triad of the serine hydrolases. Additionally, four cysteine residues were shown to interact with some enzyme inhibitors [151-153]. Thus for instance, $\mathrm{N}$-arachidonoylmaleimide, disulfiram and octhilinone were developed as MAGL inhibitors targeting those cysteine residues [151, 153,154].

Very recently, the $h$ MAGL's three dimensional structure was independently elucidated by two research teams, with a resolution of $2.2 \AA$ [155] and $2.7 \AA$ [156], respectively. The publication by Sanofi-Aventis described also a co-crystal between MAGL and SAR-629, one of their own MAGL inhibitors (87, Fig. (23)). In silico modelling of the tetrahedral intermediate between 2-AG and the active serine $[155,156]$, as well as the X-ray structure of MAGL-SAR-629 co-crystal [156], allowed important structural features to be established. i) At the surface of the enzyme, a large highly hydrophobic cavity which leads to the active site is present. This channel, made of several hydrophobic residues, apears to be suitable for interacting with the lipophilic chain of the substrate and seems to govern substrate specificity. ii) a lid (or cap) is present at the entrance of the channel. This lid is suggested to allow MAGL to interact with the cell membrane, thus helping in recruiting its lipophilic substrates from the membrane. Note that MAGL is found in both soluble and particulate fractions suggesting that the interaction between the lid and the membrane is reversible. iii) Closer to the active site a hydrophilic pocket is present and appears to be able to accommodate the substrate's glycerol moiety. This pocket, named "alcohol-binding pocket" [155] or "exit-hole" [156] by the two groups, contains three residues Ala51 (Ala61 in Sanofi's paper), His121 (His131) and Tyr194
(Tyr204), important for substrate recognition, and thus potential residues to be targeted by novel inhibitors. iv) Two non-catalytic cysteines, Cys201 (Cys211) and Cys242 (Cys252), which are supposed to be targeted by Michaelacceptor inhibitors, are in the vicinity of the catalytic site. Cys242 (Cys252) lies very close to the active Ser, deeply buried in the catalytic pocket, and Cys201 (Cys211) is farther from the active serine but remains accessible to inhibitors from the active site. On the contrary, Cys208 (Cys218) is described as pointing toward the outside of the enzyme. It is expected that these crystal structures will aid the development of novel MAGL inhibitors.

\section{III.2. Pharmacology of 2-AG or why Inhibiting MAGL Hydrolase Activity?}

2-AG is present at high levels in the brain, where it exerts an important role in controlling neurotransmitters release, and is also present in the periphery throughout the organism. (For a review see [157]) Indeed, beside its role as transmitter, 2-AG is an intermediate in lipid metabolism and, very likely, only a limited fraction of the 2-AG available acts as lipid mediator. Among the proposed roles for $2-\mathrm{AG}$, it was demonstrated to be involved in various processes like neuroprotection [158-160], appetite [161], cognitive and affective behaviours, or nociception [162] and inflammation, resulting from CNS and peripheral system locations, respectively. (for a complete review, see [157]) Furthermore, several studies demonstrated the involvement of 2-AG in controlling cell proliferation and invasion, suggesting that MAGL inhibitors could be relevant in cancer treatment [163, 164]. Preclinical studies suggested that MAGL inhibition could represent an interesting strategy for treating pain [20, 36, 165, 166, 167], 

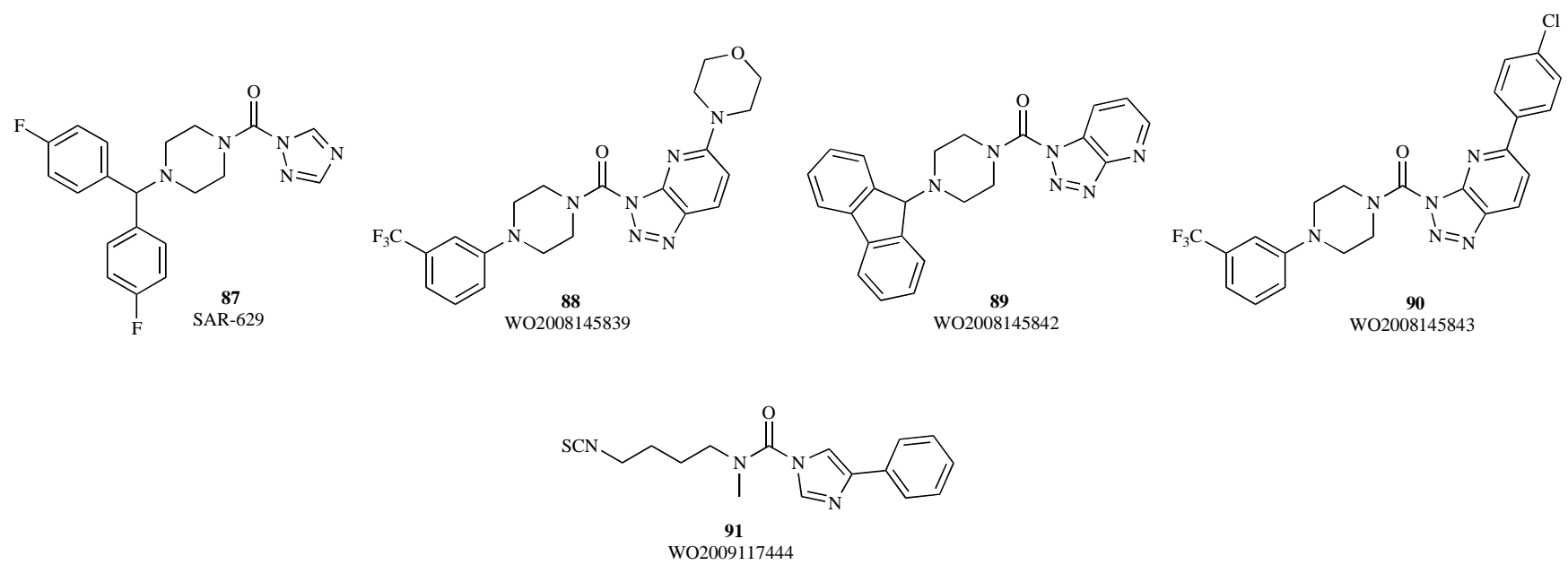

Fig. (23). Urea-type MAGL inhibitors.

inflammation [37, 166, 168], vomiting, nausea [169] and anxiety [40]. Investigations for MAGL inhibitors are more recent that those on FAAH, resulting in a limited number of inhibitors (see [54, 170]). Below we will review the available patents describing MAGL inhibitors.

\section{III.3. MAGL Inhibitors}

\section{III.3.1. Urea-based MAGL Inhibitors}

Sanofi-Aventis was the first pharmaceutical company which published MAGL inhibitors. Urea-based compounds bearing piperazinyl and triazole or triazolopyridine moieties as substituents were designed and developed.

Compounds 88 [104], 89 [171] and 90 [103] (Fig. (23)) were found to inhibit $m \mathrm{MAGL}$ at nanomolar concentrations $\left(\mathrm{IC}_{50}\right.$ values of $4 \mathrm{nM}, 4 \mathrm{nM}$ and $2 \mathrm{nM}$ for $\mathbf{8 8}, \mathbf{8 9}$ and 90 , respectively) and to exhibit either selectivity for MAGL over FAAH, or dual nanomolar inhibition of both enzymes. Makriyannis' group at Northearsten University also disclosed several urea-based MAGL inhibitors such as $91\left(\mathrm{IC}_{50}\right.$ $=42 \mathrm{nM}$ against $h \mathrm{MAGL})$ [172]. Note that, due to its isothiocyanate function, this compound could be useful as a covalent probe to explore MAGL properties, and notably the cysteine residues.

\section{III.3.2. Carbamate-based MAGL Inhibitors}

Piomelli's group reported the ability of a carbamate derivative, URB602 (92, Fig. (24)), to inhibit MAGL $\left(\mathrm{IC}_{50}\right.$ value of $28 \mu \mathrm{M}$ ) [173]. However, this compound lacks selectivity since it inhibits FAAH with a similar potency [174, 175].

Much more recently, by screening its own library of carbamates, Cravatt's group found piperidinyl and piperazinyl carbamates which were able to inhibit MAGL without affecting FAAH activity [176]. The authors demonstrated that an increased steric hindrance improved the selectivity toward MAGL. This work resulted in the design of a selective and potent MAGL inhibitor with the synthesis of compound JZL184 ((93, Fig. (24)) [177, 178]. Indeed, with the incorporation of two oxygen atoms in the 3 and 4 positions of the phenyl rings, they obtained an excellent selectivity in the range of 400 -fold ( $\mathrm{IC}_{50}$ values of $10 \mathrm{nM}$ and $4690 \mathrm{nM}$ for MAGL and FAAH, respectively). In addition, inspired by the selective piperazinyl urea-based FAAH inhibitor 32 (PF622, Fig. (10)) and by 93, Cravatt et al. developed a series of compounds, such as 94 (JZL195, Fig. (24)), which inhibited FAAH and MAGL with a similar potency without affecting other serine hydrolases ( $\mathrm{IC}_{50}$ values of 13 and $19 \mathrm{nM}$ for FAAH and MAGL, respectively) [9].

Today, compound $\mathbf{9 3}$ is extensively used as a reference pharmacological tool to study the effects of MAGL inhibition. Several publications report the use of $\mathbf{9 3}$ for increasing 2-AG levels and the resulting effects, for instance, in cancer pathogenesis [164], neuropathic pain [36], anxiety [40] and colon inflammation [168].

\section{III.3.3. MAGL Inhibitors of Miscellaneous Structure}

MAGL inhibitors based on an activated ketone were described by Makriyannis' group at Northeastern University. The $\alpha$-keto oxadiazole derivatives, such as $\mathbf{9 7}$, are quite active against MAGL, although they remain more active against FAAH (Fig. (25), $\mathrm{IC}_{50}=71 \mathrm{nM}$ and $\mathrm{K}_{\mathrm{i}}=17 \mathrm{nM}$ against $h$ FAAH) [179].

Janssen Pharmaceuticals published a series of three patents describing MAGL inhibitors based on an amide function. Each patent is illustrated with a lead compound (98-100, Fig. (25)) that inhibit MAGL with an $\mathrm{IC}_{50}$ value of $10.4 \mathrm{nM}, 10 \mathrm{nM}$ and $50 \mathrm{nM}$, respectively) which was tested in various in-vitro and/or in-vivo pharmacological evaluations [180-182]. Thus for instance, 98 was able to increase 2AG levels in an ex-vivo preparation of rat brain. In-vivo, compound 98 (30 mg/kg, po) completely prevented the CFA-induced heat hypersensitivity and partially the CFAinduced pressure hypersensitivity. Compound 99 was similarly tested in various experimental models to assess its antinociceptive properties. The group also published crystal structures of different MAGL mutants and co-crystallised forms with compounds $\mathbf{9 9}$ and $\mathbf{1 0 0}$ with resolutions of 1.35 and $2.3 \AA$, respectively $[183,184]$. 


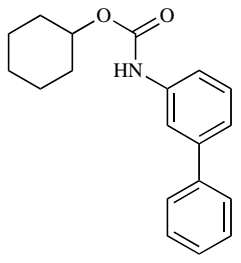

92

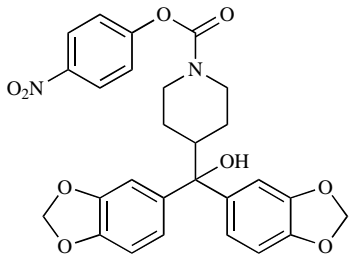

93 (JZL184)

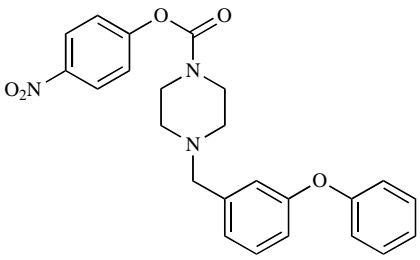

94 (JZL195)

Fig. (24). Carbamate-type MAGL inhibitors.
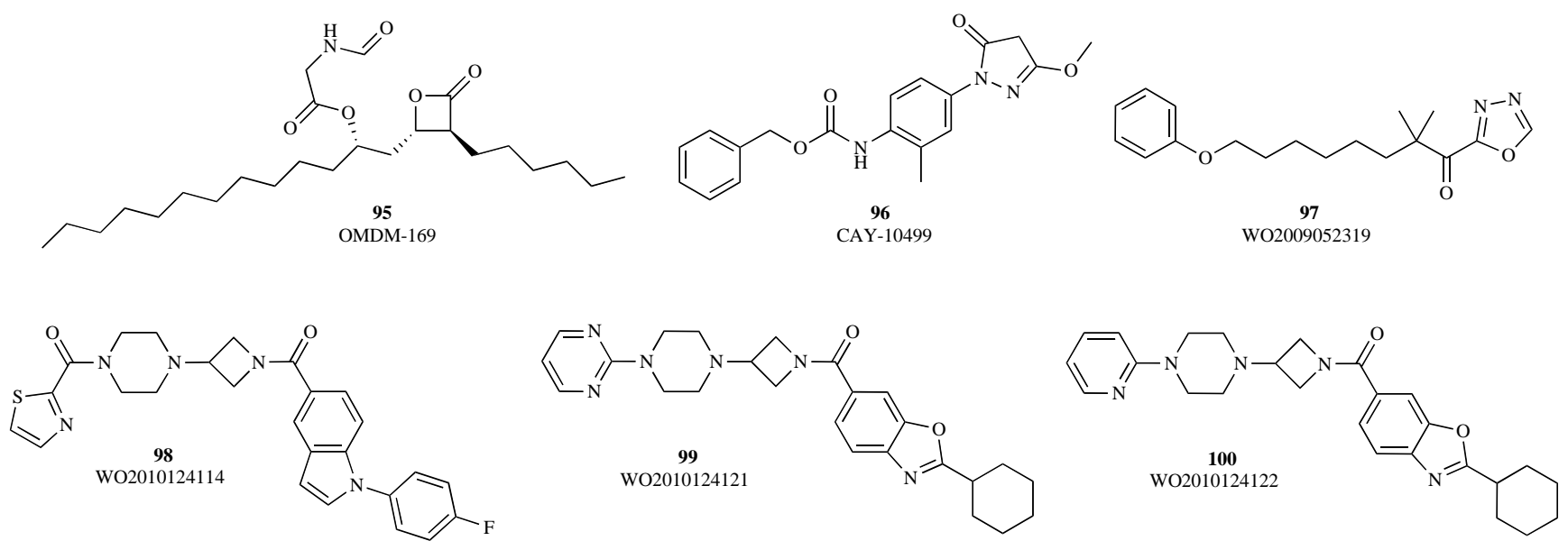

Fig. (25). MAGL inhibitors of various structures.

\section{III.3.4. Other Recent Structures Not Covered by Patents}

A $\beta$-lactone inspired from the serine hydrolase inhibitor, tetrahydrolipstatin, was designed by Di Marzo's group. OMDM169 (95, Fig. (25)) inhibits $h$ MAGL with an $\mathrm{IC}_{50}$ value of $0.89 \mu \mathrm{M}$ in a competitive manner. However, the authors also disclosed that compound 95 also inhibits $r$ FAAH with an $\mathrm{IC}_{50}$ value of $3.0 \mu \mathrm{M}$ [165]. Also of interest, is the finding that the 5-methoxy-1,3,4-oxadiazol-2(3H)-one moiety (96, Fig. (25)) is also able to inhibit MAGL activity, thus offering an additional template for the development of inhibitors of the enzyme $[185,186]$.

\section{IV. $N$-ACYLETHANOLAMINE ACID AMIDASE}

\section{IV.1. NAAA, Structure and Mechanism}

Like FAAH, the $N$-Acylethanolamine-hydrolyzing Acid Amidase (NAAA) is also able to cleave amide bonds of saturated and unsaturated NAEs [8]. NAAA is thought to exert almost all of its hydrolytic activity towards PEA (Fig. (2)) since other NAEs are hydrolysed at much lower rates [187]. Moreover, it is notable that NAAA does not hydrolyse 2AG. Although NAAA, like FAAH, exerts its activity towards NAEs, there is no sequence homology between these two enzymes, and whereas the optimum $\mathrm{pH}$ for FAAH activity is around 9, NAAA's activity is the highest at pH 5 [188, 189]. This is actually consistent with the subcellular localisation of NAAA in the lysosomes [189, 190]. Moreover, NAAA shares high sequence homology with the human acid ceramidase family, and its mode of action and structural features are closer to those of this hydrolase family than to FAAH [191]. For instance, similarly to what is found for the choloylglycine hydrolase superfamily [192], and more precisely for the acid ceramidase family, the precursor form of NAAA is auto-catalytically cleaved into two subunits, $\alpha$ and $\beta$, at acidic $\mathrm{pH}$. Then, this cleavage leads to the appearance of the unmasked $N$-terminal nucleophilic residue responsible for the catalytic activity of NAAA [193]. Wang et al. also identified Cys126 as the $N$-terminal residue and Cys126/ Arg142/Asp154 as the residues constituting the catalytic triad of the human NAAA. As a consequence, the strategy for NAAA targeting is mainly based on the cysteine hydrolase activity of the enzyme, contrasting to the strategies used to target the serine hydrolases of the endocannabinoid system (i.e. FAAH, MAGL, and ABHD6). Because the discovery and initial characterisation of NAAA are quite recent, only a very limited number of studies have been published to date.

\section{IV.2. Pharmacology of PEA or why Inhibiting NAAA Hydrolase Activity?}

Several studies suggested that the role of NAAA is to regulate NAEs levels in macrophages and peripheral tissues [194]. As PEA is NAAA's primary substrate, its inhibition appears to be a relevant alternative to FAAH inhibition in the induction of anti-inflammatory [195], analgesic [27, 28] and neuroprotective effects [196]. Indeed, these effects can be mediated by PEA through receptors that are distinct from cannabinoid receptors (e.g. PPAR $\alpha$ ) [197]. 


\section{IV.3. NAAA Inhibitors}

\section{IV.3.1. Substrate-like NAAA Inhibitors}

The initial studies on NAAA inhibitors consisted in the synthesis of substrate analogues. Thus esters (101 and 106, $\mathrm{IC}_{50}$ values of 19 and $10 \mu \mathrm{M}$ respectively, Fig. (26)), retroesters $\left(\mathbf{1 0 2}, \mathrm{IC}_{50}\right.$ value of $53.8 \mu \mathrm{M}$, Fig. (26)), amides and retroamides $\left(\mathbf{1 0 3}, 104\right.$ and $\mathbf{1 0 5}, \mathrm{IC}_{50}$ values of $31.8,4.5$ and $8.3 \mu \mathrm{M}$ respectively, Fig. (26)) of palmitic acid were developed [198-201].

Compounds 101, 102 and 103 were tested against $r$ FAAH and $r$ NAAA (solubilised from the $12000 * \mathrm{~g}$ pellet of rat lung homogenates) and were found to be selective at 100 $\mu \mathrm{M}$ for NAAA versus FAAH $(84,71$ and $77 \%$ of NAAA inhibition versus 36,0 and $8 \%$ of FAAH inhibition, for compounds 101, 102 and $\mathbf{1 0 3}$ respectively) [198, 199]. Similarly, compounds $\mathbf{1 0 4}$ and $\mathbf{1 0 5}$ do not inhibit FAAH at 100 $\mu \mathrm{M}$. The inhibition mechanism of $\mathbf{1 0 4}$ was further investigated and 104 was found to act by a reversible and noncompetitive mechanism. This compound was also shown to inhibit NAAA in intact macrophages and in macrophage homogenates [200].

More recently, another study based on PEA analogues has been published. The authors used recombinant $r$ NAAA expressed in HEK cells to test novel series of NAAA inhibitors. Among the assayed compounds, 106 (Fig. (26)) was found to be a selective and competitive NAAA inhibitor [201].

\section{IV.3.2. $\beta$-lactone-based Inhibitors}

To date, and to our knowledge, the only inhibitors known for inhibiting NAAA with a sub-micromolar activity are based on the $\beta$-lactone template.

Compounds 107 and 108 (Fig. (27)) [202] were found to inhibit $r$ NAAA (recombinant HEK cells expressing rNAAA) in a non-competitive and reversible manner with $\mathrm{IC}_{50}$ values of 115 and $420 \mathrm{nM}$, respectively. As no crystal structure of NAAA is available, the authors built a model of NAAA catalytic site based on its high homology with conjugated bile acid hydrolase (CBAH). This model, which was validated by the docking of the tetrahedral intermediate between PEA and

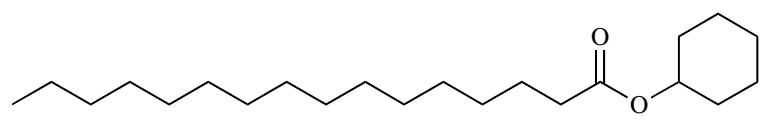

101<smiles>CCCCCCCCCCCCCCCNC(=O)CCO</smiles><smiles>CCCCCCCCCCCCCCCNC(=O)c1ccccc1</smiles>

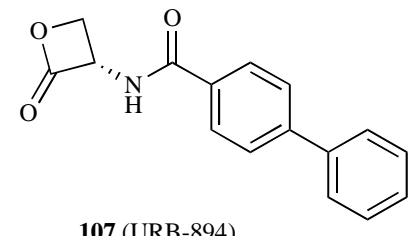<smiles>O=C(CCc1ccccc1)N[C@H]1COC1=O</smiles>
WO2009049238
108 (URB-783) WO2009049238

Fig. (27). $\beta$-lactone-type NAAA inhibitors.

Cys131 (rNAAA), is to date, the only tool available for designing new inhibitors of NAAA [203]. Compound $\mathbf{1 0 7}$ [204] as well as compound $\mathbf{1 0 8}$ [202] exhibited antiinflammatory effects in various inflammation models where URB597 (KDS-4103 or 10, Fig. (5)) had no effect, suggesting that NAAA is solely implicated.

\section{CURRENT AND FUTURE DEVELOPMENTS}

When looking at the variety of compounds described here, it is safe to say that we now have the tools to fully explore the consequences of FAAH and MAGL selective inhibition. The early thinking was that using an inhibitor would allow to increase local levels of endocannabinoids due to their on-demand production. However, it appears that the administration of a FAAH or MAGL inhibitor results in increased endocannabinoid levels throughout the body (see for instance $[205,206])$. Although this results in a situation not that different from agonist administration, advantages of inhibiting the endocannabinoid hydrolysing enzymes still exist. First, by selectively inhibiting FAAH or MAGL only a subset of the effects obtained following agonists administration are observed. Thus when looking at the cannabinoid tetrad of effects [23] - i.e. antinociception, catalepsy, hypolocomotion, hypothermia - all the effects are present following $\mathrm{CB}_{1}$ agonist administration, but only antinociception is induced upon FAAH inhibition. Another interesting point is that neither selective FAAH inhibition nor selective MAGL inhibition induce a cataleptic behaviour in mice. However, upon blockade of both enzymes catalepsy is present, as it is following $\mathrm{CB}_{1}$ agonist administration (Table $\mathbf{1}$, and see [9]).
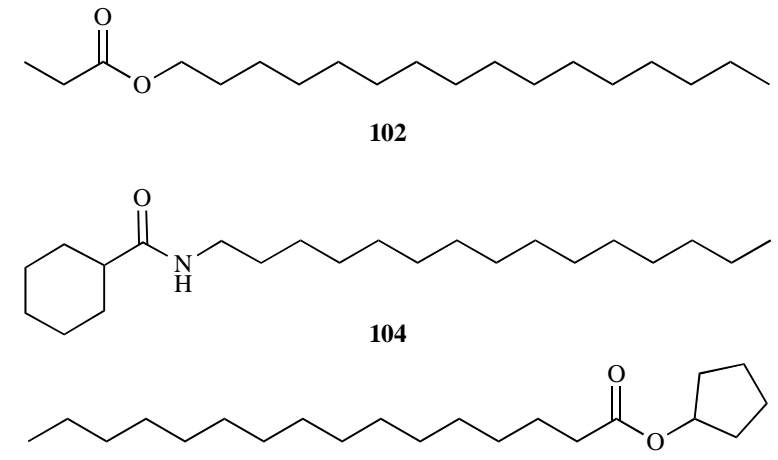

106

Fig. (26). Substrate-based NAAA inhibitors. 
Table 1.

\begin{tabular}{|l|c|c|c|}
\hline & $\begin{array}{c}\text { FAAH } \\
\text { Inhibition }\end{array}$ & $\begin{array}{c}\text { MAGL } \\
\text { Inhibition }\end{array}$ & $\begin{array}{c}\text { FAAH/MAGL } \\
\text { Dual Inhibition }\end{array}$ \\
\hline \hline Antinociception & + & + & +++ \\
\hline Catalepsy & - & - & ++ \\
\hline Hypolocomotion & - & + & + \\
\hline Hypothermia & - & - & - \\
\hline
\end{tabular}

Based on the published studies, it appears that FAAH inhibition generates less CNS-related side effects compared to MAGL inhibition. Thus for instance MAGL, but not FAAH, inhibition reduces locomotion. Another difference between MAGL and FAAH inactivation is the adaptations in $\mathrm{CB}_{1}$ signalling observed following MAGL, but not FAAH, complete and chronic inhibition [207, 208]. These adaptations, resulting in functional antagonism of the endocannabinoid system, provoke a lower analgesic effect upon MAGL chronic inhibition compared to FAAH inhibition, even though acute MAGL inhibition induces similar effects than acute FAAH inhibition [208]. Based on these studies, it has been suggested, but has not been demonstrated yet, that partial blockade of MAGL could preserve its analgesic potential also during chronic administration.

It is also worth noting, that FAAH inhibition seems to be safe although a large number of bioactive lipids, besides NAEs, are hydrolysed by the enzyme. For instance, chronic inhibition of FAAH increases NAE levels, but also $N$ acyltaurines which are transient receptor potential channels agonists [206]. Conversely, brain levels of the GPR18 receptor endogenous agonist $N$-arachidonoylglycine are decreased following FAAH inhibition.[19] The question whether MAGL inhibition results in the exclusive modulation of monoacylglycerols (and corresponding fatty acids) [178, 205] remains open. Of great interest is the recent demonstration that MAGL-produced arachidonic acid is further metabolized in prostaglandins. Thus inhibition of MAGL results in increased levels of 2-AG, but also in decreased prostaglandins levels, further supporting MAGL as an interesting anti-inflammatory target [209].

Because NAEs (e.g. anandamide and $N$ palmitoylethanolamine) and 2-AG levels are profoundly affected throughout the body by FAAH and MAGL, respectively, inhibition, one could question the interest in pursuing inhibitors of the additional endocannabinoid hydrolysing enzymes (NAAA, ABHD6, ABHD12). One argument in favour of these enzymes can be found in the localisation of specific enzymes at the tissue and cell level. This results in enzymes controlling pools of signalling mediator. Thus, although MAGL controls $85 \%$ of 2-AG hydrolysis in whole brain homogenates, ABHD6 selective inhibition [210-212] in intact neurons and in brain slices results in increased 2AG levels and 2-AG induced-synaptic plasticity, respectively [7]. Note that it was also recently demonstrated that carboxylesterase-1 (CES-1) participates in the control of 2AG metabolisms in macrophages [213]. When looking at NAAA, its inhibition in intact macrophages reduces AEA degradation to a similar, if not higher, extent than FAAH inhibition [202, 214]. These two examples underscore the potential of targeting NAAA, ABHD6, and perhaps ABHD12, to more precisely fine-tune endocannabinoid levels in a subset of cells inside a tissue. Thus, in addition to advancing the development of FAAH and MAGL inhibitors from bench to bedside, efforts aiming at inhibiting the other endocannabinoid-hydrolyzing enzymes should bring exciting new developments in the endocannabinoid field.

\section{CONFLICT OF INTEREST}

The authors do not have any conflict of interest.

\section{ACKNOWLEDGEMENTS}

\section{N/A.}

\section{REFERENCES}

[1] Muccioli GG. Endocannabinoid biosynthesis and inactivation, from simple to complex. Drug Discov Today 2010; 15(11-12): 474-83.

[2] CravattBF, Giang DK, Mayfield SP, Boger DL, Lerner RA,Gilula NB. Molecular characterization of an enzyme that degrades neuromodulatory fatty-acid amides. Nature 1996; 384(6604): 83-7.

[3] Dinh TP, Carpenter D, Leslie FM, Freund TF, Katona I, Sensi SL et al. Brain monoglyceride lipase participating in endocannabinoid inactivation. Proc Natl Acad Sci 2002; 99(16): 10819-24.

[4] Dinh TP, Kathuria S, Piomelli D. RNA interference suggests a primary role for monoacylglycerol lipase in the degradation of the endocannabinoid 2-arachidonoylglycerol. Mol Pharmacol 2004; 66(5): 1260-4.

[5] Wei BQ, Mikkelsen TS, McKinney MK, Lander ES,Cravatt BF. A second fatty acid amide hydrolase with variable distribution among placental mammals. J Biol Chem 2006; 281(48): 36569-78.

[6] Blankman JL, Simon GM,Cravatt BF. A comprehensive profile of brain enzymes that hydrolyze the endocannabinoid 2arachidonoylglycerol. Chem Biol 2007; 14: 1347-56.

[7] Marrs WR, Blankman JL, Horne EA, Thomazeau A, Lin YH, Coy $\mathrm{J}$, et al. The serine hydrolase ABHD6 controls the accumulation and efficacy of 2-AG at cannabinoid receptors. Nat Neurosci 2010; 13(8): 951-7.

[8] Ueda N, Tsuboi K, Lambert DM. A second N-acylethanolamine hydrolase in mammalian tissues. Neuropharmacol 2005; 48(8): 1079-85.

[9] Long JZ, Nomura DK, Vann RE, Walentiny DM, Booker L, Jin X, et al. Dual blockade of FAAH and MAGL identifies behavioral processes regulated by endocannabinoid crosstalk in vivo. Proc Natl Acad Sci 2009; 106(48): 20270-5.

[10] Patricelli MP,Cravatt BF. Fatty acid amide hydrolase competitively degrades bioactive amides and esters through a nonconventional catalytic mechanism. Biochem1999; 38(43): 14125-30.

[11] Patricelli MP, Lovato MA,Cravatt BF. Chemical and mutagenic investigations of fatty acid amide hydrolase: Evidence for a Family of Serine Hydrolases with Distinct Catalytic Properties $\dagger$. Biochemistry 1999; 38(31): 9804-9812.

[12] Giang DK,Cravatt BF, Molecular characterization of human and mouse fatty acid amide hydrolases. Proc. Natl. Acad. Sci. U.S.A. 1997; 94(6): 2238-2242.

[13] Fowler CJ, Jonsson K-O,Tiger G. Fatty acid amide hydrolase: biochemistry, pharmacology, and therapeutic possibilities for an enzyme hydrolyzing anandamide, 2-arachidonoylglycerol, palmitoylethanolamide, and oleamide. Biochem Pharmacol 2001; 62(5): 517-26.

[14] Bisogno T, De Petrocellis L, Di Marzo V. Fatty acid amide hydrolase, an enzyme with many bioactive substrates. Possible therapeutic implications. Curr Pharm Des 2002; 8: 533-47.

[15] Saghatelian A, McKinney MK, Bandell M, Patapoutian A, Cravatt BF. A FAAH-regulated class of N-Acyl Taurines that activates TRP ion channels. Biochem 2006; 45(30): 9007-15.

[16] Patricelli MP, Patterson JE, Boger DL,Cravatt BF. An endogenous sleep-inducing compound is a novel competitive inhibitor of fatty acid amide hydrolase. Bioorg Med Chem Lett 1998; 8(6): 613-8. 
[17] Fowler CJ. Oleamide: a member of the endocannabinoid family? Br. J Pharmacol 2004; 141(2): 195-6.

[18] Hu SS-J, Bradshaw HB, Benton VM, Chen JS-C, Huang SM, Minassi A, et al. The biosynthesis of $\mathrm{N}$-arachidonoyl dopamine (NADA), a putative endocannabinoid and endovanilloid, via conjugation of arachidonic acid with dopamine. Prostaglandins Leukot Essent Fatty Acids 2009; 81(4): 291-301.

[19] Bradshaw H, Rimmerman N, Hu S, Benton V, Stuart J, Masuda K, et al. The endocannabinoid anandamide is a precursor for the signaling lipid $\mathrm{N}$-arachidonoyl glycine by two distinct pathways. Biochem 2009; 10(1): 14

[20] Kinsey SG, Long JZ, Cravatt BF, Lichtman AH. Fatty acid amide hydrolase and monoacylglycerol lipase inhibitors produce antiallodynic effects in mice through distinct cannabinoid receptor mechanisms. J Pain 2010; 11(12): 1420-8.

[21] Alexander SPH, Kendall DA. The complications of promiscuity: endocannabinoid action and metabolism. Br J Pharmacol 2007; 152(5): 602-23.

[22] Pacher P, Bátkai S, Kunos G. The endocannabinoid system as an emerging target of pharmacotherapy. Pharmacol Rev 2006; 58(3): $389-462$.

[23] Smith PB, Compton DR, Welch SP, Razdan RK, Mechoulam R, Martin BR. The pharmacological activity of anandamide, a putative endogenous cannabinoid, in mice. J Pharmacol Exp Ther 1994; 270(1): 219-27.

[24] Godlewski G, Alapafuja SO, Bátkai S, Nikas SP, Cinar R, Offertáler L, et al. Inhibitor of fatty acid amide hydrolase normalizes cardiovascular function in hypertension without adverse metabolic effects. Chem Biol 2010; 17(11): 1256-66.

[25] Bashashati M, Storr MA, Nikas SP, Wood JT, Godlewski G, Liu J, et al. Inhibiting fatty acid amide normalizes endotoxin-induced enhanced gastrointestinal motility in the mouse. Br J Pharmacol 2011: accepted article.

[26] Hansen HS, Diep TA. N-acylethanolamines, anandamide and food intake. Biochem Pharmacol 2009; 78(6): 553-60.

[27] Calignano A, Rana GL, Giuffrida A, Piomelli D. Control of pain initiation by endogenous cannabinoids. Nature 1998; 394(6690): 277-81.

[28] Jaggar SI, Hasnie FS, Sellaturay S, Rice ASC. The antihyperalgesic actions of the cannabinoid anandamide and the putative CB2 receptor agonist palmitoylethanolamide in visceral and somatic inflammatory pain. Pain 1998; 76(1-2): 189-99.

[29] Parolaro D, Realini N, Vigano D, Guidali C, Rubino T. The endocannabinoid system and psychiatric disorders. Exp Neurol 2010; 224(1): 3-14.

[30] Bisogno T, Sepe N, De Petrocellis L, Mechoulam R, Di Marzo V. The sleep inducing factor oleamide is produced by mouse neuroblastoma cells. Biochem Biophys Res Commun 1997; 239(2): 473-9.

[31] Boger DL, Henriksen SJ, Cravatt BF. Oleamide: an endogenous sleep-inducing lipid and prototypical member of a new class of biological signaling molecules. Curr Pharm Des 1998; 4: 303-14.

[32] Lambert DM, Vandevoorde S, Jonsson K-O, Fowler CJ. The palmitoylethanolamide family: A new class of anti-inflammatory agents? Curr Med Chem 2002; 9: 663-74.

[33] Thabuis C, Tissot-Favre D, Bezelgues J-B, Martin J-C, CruzHernandez C, Dionisi F, et al. Biological Functions and Metabolism of Oleoylethanolamide. Lipids 2008; 43(10): 887-94.

[34] Fu J, Gaetani S, Oveisi F, Lo Verme J, Serrano A, Rodriguez de Fonseca F, et al. Oleylethanolamide regulates feeding and body weight through activation of the nuclear receptor PPAR-[alpha]. Nature 2003; 425(6953): 90-3.

[35] Schlosburg J, Carlson B, Ramesh D, Abdullah R, Long J, Cravatt $\mathrm{B}$, et al. Inhibitors of endocannabinoid-metabolizing enzymes reduce precipitated withdrawal responses in THC-dependent mice. AAPS J 2009; 11(2): 342-52.

[36] Kinsey SG, Long JZ, O'Neal ST, Abdullah RA, Poklis JL, Boger DL, et al. Blockade of endocannabinoid-degrading enzymes Attenuates neuropathic pain. J Pharmacol Exp Ther 2009; 330(3): 902-10.

[37] Jhaveri MD, Richardson D, Chapman V. Endocannabinoid metabolism and uptake: novel targets for neuropathic and inflammatory pain. Br J Pharmacol 2007; 152(5): 624-32.

[38] Ezzili C, Mileni M, McGlinchey N, Long JZ, Kinsey SG, Hochstatter DG, et al. Reversible competitive $\alpha$-ketoheterocycle inhibitors of fatty acid amide hydrolase containing additional conformational constraints in the acyl side chain: Orally active, long-acting analgesics. J Med Chem 2011; 54(8): 2805-22.

[39] Ahn K, Smith SE, Liimatta MB, Beidler D, Sadagopan N, Dudley $\mathrm{DT}$, et al. Mechanistic and pharmacological characterization of PF04457845: A highly potent and selective fatty acid amide hydrolase inhibitor that reduces inflammatory and noninflammatory pain. J Pharmacol Exp Ther 2011; 338(1): 114-24.

[40] Kinsey SG, O'Neal ST, Long JZ, Cravatt BF, Lichtman AH. Inhibition of endocannabinoid catabolic enzymes elicits anxiolyticlike effects in the marble burying assay. Pharmacol Biochem Behay 2011; 98(1): 21-7.

[41] Hill MN, Hillard CJ, Bambico FR, Patel S, Gorzalka BB,Gobbi G. The therapeutic potential of the endocannabinoid system for the development of a novel class of antidepressants. Trends Pharmacol Sci 2009; 30(9): 484-93

[42] Gaetani S, Dipasquale P, Romano A, Righetti L, Cassano T, Piomelli D, et al. International review of neurobiology. G. Bagetta, M.T. Corasaniti, T. Sakurada, and S. Sakurada 2009: 57-72.

[43] Bracey MH, Hanson MA, Masuda KR, Stevens RC,Cravatt BF. Structural adaptations in a membrane enzyme that terminates endocannabinoid signaling. Sci 2002; 298(5599): 1793-6.

[44] McKinney MK,Cravatt BF. Structure and function of fatty acid amide hydrolase. Annu Rev Biochem 2005; 74: 411-32.

[45] Michaux C, Labar G. Fatty acid amide hydrolase : from characterisation to therapeutics. Chem Biodivers 2007; 4: 1882902.

[46] Mileni M, Johnson DS, Wang Z, Everdeen DS, Liimatta M, Pabst $\mathrm{B}$, et al. Structure-guided inhibitor design for human FAAH by interspecies active site conversion. Proc Natl Acad Sci U.S.A. 2008; 105(35): 12820-4

[47] Ahn K, Johnson DS, Mileni M, Beidler D, Long JZ, McKinney MK, et al. Discovery and characterization of a highly selective FAAH inhibitor that reduces inflammatory Pain Chem Biol 2009; 16(4): 411-20.

[48] Mileni M, Garfunkle J, DeMartino JK, Cravatt BF, Boger DL,Stevens RC. Binding and inactivation mechanism of a humanized fatty acid amide hydrolase by $\alpha$-Ketoheterocycle Inhibitors Revealed from Cocrystal Structures. J. Am. Chem. Soc. 2009; 131(30): 10497-10506.

[49] Mileni M, Garfunkle J, Ezzili C, Kimball FS, Cravatt BF, Stevens $\mathrm{RC}$, et al. X-ray crystallographic analysis of $\alpha$-Ketoheterocycle inhibitors bound to a humanized variant of fatty acid amide hydrolase. J Med Chem 2010; 53(1): 230-40.

[50] Mileni M, Kamtekar S, Wood DC, Benson TE, Cravatt BF,Stevens RC. Crystal structure of fatty acid amide hydrolase bound to the carbamate inhibitor URB597: discovery of a deacylating water molecule and insight into enzyme inactivation. J Mol Biol 2010; 400(4): 743-54.

[51] Feledziak M, Michaux C, Urbach A, Labar G, Muccioli GG, Lambert DM, et al. $\beta$-Lactams derived from a carbapenem chiron are selective inhibitors of human fatty acid amide hydrolase versus human monoacylglycerol lipase. J Med Chem 2009; 52(22): 705468.

[52] Seierstad M, Breitenbucher JG. Discovery and development of fatty acid amide hydrolase (FAAH) Inhibitors J Med Chem 2008; 51(23): 7327-43

[53] Vandevoorde S. Overview of the chemical families of fatty acid amide hydrolase and monoacylglycerol lipase inhibitors. Curr Top Med Chem 2008; 8: 247-67.

[54] Minkkila A, Saario SM, Nevalainen T. Discovery and development of endocannabinoid-hydrolyzing enzyme inhibitors. Curr Top Med Chem 2010; 10(8): 828-58.

[55] Deng HF. Recent advances in the discovery and evaluation of fatty acid amide hydrolase inhibitors. Expert Opin Drug Dis 2010; 5(10): 961-93.

[56] Boger DL, Sato H, Lerner AE, Hedrick MP, Fecik RA, Miyauchi $\mathrm{H}$, et al. Exceptionally potent inhibitors of fatty acid amide hydrolase: the enzyme responsible for degradation of endogenous oleamide and anandamide. Proc Natl Acad Sci U.S.A. 2000; 97(10): 5044-9.

[57] Tarzia G, Duranti A, Tontini A, Piersanti G, Mor M, Rivara S, et al. Design, synthesis, and structure-activity relationships of alkylcarbamic acid aryl esters, a new class of fatty acid amide hydrolase inhibitors. J Med Chem 2003; 46(12): 2352-60.

[58] Ahn K, Johnson DS, Fitzgerald LR, Liimatta M, Arendse A, Stevenson $\mathrm{T}$, et al. Novel mechanistic class of fatty acid amide 
hydrolase inhibitors with remarkable selectivity. Biochemistry 2007; 46(45): 13019-13030.

[59] Edwards PD, Meyer EF, Vijayalakshmi J, Tuthill PA, Andisik DA, Gomes B, et al. Design, synthesis, and kinetic evaluation of a unique class of elastase inhibitors, the peptidyl .alpha.ketobenzoxazoles, and the x-ray crystal structure of the covalent complex between porcine pancreatic elastase and Ac-Ala-Pro-Val2-benzoxazole. J Am Chem Soc 1992; 114(5): 1854-63.

[60] Edwards PD, Wolanin DJ, Andisik DW, Davis MW. Peptidyl alpha-ketoheterocyclic inhibitors of human neutrophil elastase. 2 . Effect of varying the heterocyclic ring on in vitro potency. J Med Chem 1995; 38(1): 76-85.

[61] Boger, D.L. Oxadiazole ketones as inhibitors of fatty acid amide hydrolase, their preparation, pharmaceutical compositions, and use in therapy. WO2006044617 (2006).

[62] Boger, D.L. Preparation of phenylheteroaryloxadiazolylheptanone derivatives and analogs for use as FAAH inhibitors. WO2010005572 (2010).

[63] Boger, D. . Preparation of keto-oxazole compounds as modulators of fatty acid amide hydrolase. WO2007098142 (2007).

[64] Boger, D.L. Preparation of oxazole derivatives as fatty acid amide hydrolase inhibitors. WO2008030532 (2008)

[65] Boger, D.L. Tetracyclic compounds as inhibitors of fatty acid amide hydrolase and their preparation, pharmaceutical compositions and use in the treatment of diseases. WO2008147553 (2008).

[66] Boger, D.L. Preparation of oxazole derivatives as inhibitors of fatty acid amide hydrolase (FAAH). WO2008150492 (2008).

[67] Apocada, R., Breintenbucher, J.G., Epperson, M.T., Fried, A.K., Pippel, D. J., Seierstad, M. 2-keto-oxazoles as modulators of fatty acid amide hydrolase WO2007061862 (2007).

[68] Apodaca, R., Breitenbucher, J. G., Chambers, A. L., Seierstad, M.,Xiao, W. Preparation of oxazolyl piperidinyl methanones as modulators of fatty acid amide hydrolase. WO2007140005 (2007).

[69] Alexander JP,Cravatt BF. Mechanism of carbamate inactivation of FAAH: Implications for the design of covalent inhibitors and in vivo functional probes for enzymes. Chem Biol 2005; 12(11): 1179-87.

[70] Mor M, Rivara S, Lodola A, Plazzi PV, Tarzia G, Duranti A, et al. Cyclohexylcarbamic Acid 3'- or 4'-Substituted Biphenyl-3-yl Esters as fatty acid amide hydrolase inhibitors: synthesis, quantitative structure-activity relationships, and molecular modeling studies. J Med Chem 2004; 47(21): 4998-5008.

[71] Piomelli, D., Duranti, A., Tontini, A., Mor, M.,Tarzia, G. Preparation and use of carbamates for modulation of anxiety through blockade of anandamide hydrolysis. WO2004033422 (2004).

[72] Dasse, O., Putman, D., Compton, T. R.,Parrott, J. A. Metabolically stabilized inhibitors of fatty acid amide hydrolase, and use in the treatment of pain. WO2008063714 (2008).

[73] Dasse, O., Putman, D.,Compton, T., R Ionizable inhibitors of fatty acid amide hydrolase WO2008020866 (2008).

[74] Dasse, O. Combination FAAH inhibitor and analgesic, antiinflammatory or anti-pyretic agent. WO2008021625 (2008).

[75] Dasse, O., Putman, D., Compton, T. R., Parrott, J. Alkylcarbamic acid ester inhibitors of fatty acid amide hydrolase, and therapeutic use. WO2007079180 (2007).

[76] Putman, D., Parrott, J., Compton, T.R., Dasse, O. Alkylcarbamic acid esters as inhibitors of fatty acid amide hydrolase. WO2008024139 (2008)

[77] Lichtman AH, Leung D, Shelton CC, Saghatelian A, Hardouin C, Boger DL, et al. Reversible inhibitors of fatty acid amide hydrolase that promote analgesia: evidence for an unprecedented combination of potency and selectivity. J Pharmacol Exp Ther 2004; 311(2): 441-8.

[78] Zhang D. Fatty acid amide hydrolase inhibitors display broad selectivity and inhibit multiple carboxylesterases as off-targets. Neuropharmacol 2007; 52: 1095-105.

[79] Tarzia G, Duranti A, Gatti G, Piersanti G, Tontini A, Rivara S, et al. Synthesis and structure-activity relationships of FAAH Inhibitors: cyclohexylcarbamic acid biphenyl esters with chemical modulation at the proximal phenyl ring. Chem Med Chem 2006; 1(1): $130-9$.

[80] Clapper JR, Vacondio F, King AR, Duranti A, Tontini A, Silva C, et al. A second generation of carbamate-based fatty acid amide hydrolase inhibitors with improved activity in vivo. Chem Med Chem 2009; 4(9): 1505-13.

[81] Clapper JR, Moreno-Sanz G, Russo R, Guijarro A, Vacondio F, Duranti A, et al. Anandamide suppresses pain initiation through a peripheral endocannabinoid mechanism. Nat Neurosci 2010; 13(10): 1265-70.

[82] Ishii, T., Sugane, T., Maeda, J., Narazaki, F., Kakefuda, A., Sato, K., Takahashi, T., Kanayama, T., Saitoh, C., Suzuki, J., Kanai, C. Preparation of pyridyl non-aromatic nitrogenated heterocyclic-1carboxylate ester derivatives as FAAH inhibitors. WO2006088075 (2006).

[83] Myllymaeki, M., Castillo-Melendez, J., Koskinen, A., Minkkilae, A., Saario, S., Nevalainen, T., Jaervinen, T., Poso, A., Salo-Ahen, O. Preparation of heterocyclic phenyl carbamates as novel FAAH inhibitors. WO2008129129 (2008).

[84] Almario-Garcia, A., George, P., Hoornaert, C., Li, A.-T., Puech, F. Alkyl, alkenyl and alkynyl carbamate derivatives, their preparation and use as fatty acid amido hydrolase (FAAH) inhibitors for treating FAAH-related pathologies. WO2006117461 (2006).

[85] Abouabdellah, A., Chereze, N., Fayol, A., Saady, M., Vache, J., Veronique, C., Yaiche, P. Carbamate derivatives of alkyl heterocycles, their preparation and use as fatty acid amido hydrolase (FAAH) inhibitors for treating FAAH-related pathologies. WO2010055267 (2010).

[86] Abouabdellah, A., Goerlitzer, J., Hamley, P., Ravet, A. Alkylthiazolyl carbamates, their preparation and use as fatty acid amido hydrolase (FAAH) inhibitors for treating FAAH-related pathologies. WO2010010288 (2010).

[87] Abouabdellah, A., Fayol, A., Lochead, A., Saady, M., Vache, J.,Yaiche, P. Cyclopenta[c]pyrrolylalkylcarbamate derivatives of 5membered heterocycles, their preparation and use as fatty acid amido hydrolase (FAAH) inhibitors for treating FAAH-related pathologies. WO2010130943 (2010).

[88] Abouabdellah, A., Even, L., Fayol, A., Vache, J.,Yaiche, P. (5Membered heterocyclyl)alkyl cyclopenta[c]pyrrolylalkylcarboxylate derivatives, their preparation and use as fatty acid amido hydrolase (FAAH) inhibitors for treating FAAH-related pathologies. WO2010130944 (2010).

[89] Abouabdellah, A., Chereze, N., Fayol, A., Lochead, A., Saady, M., Vache, J., Yaiche, P. (5-Membered heterocyclyl)alkyl 7 azaspiro[3,5]nonane-7-carboxylate derivatives, their preparation and use as fatty acid amido hydrolase (FAAH) inhibitors for treating FAAH-related pathologies. WO2010130945 (2010).

[90] Abouabdellah, A., Chereze, N., Fayol, A., Lochead, A., Saady, M., Vache, J., Yaiche, P. Azaspiranyl-alkylcarbamate derivatives of 5membered heterocycles, their preparation and use as fatty acid amido hydrolase (FAAH) inhibitors for treating FAAH-related pathologies. WO2010089510 (2010).

[91] Abouabdellah, A., Almario Garcia, A., Hoornaert, C., Li, A. T Derivatives of 1-piperazine-and 1-homopiperazine-carboxylates, preparation method thereof and use of same as inhibitors of the FAAH enzyme US2006293310 (2006).

[92] Minetti, P., Cabri, W., Dallavalle, S., Merlini, L., Penco, S., Borsini, F., Caprioli, A., Maccarrone, M. Enol carbamate derivatives as inhibitors of fatty acid amide hydrolase useful in the treatment of diseases and preparation and pharmaceutical compositions thereof. WO2009109504 (2009).

[93] Minetti, P., Cabri, W., Borsini, F., Caprioli, A., Penco, S., Dallavalle, S., Merlini, L., Maccarrone, M. Oxime carbamoyl derivatives as modulators of fatty acid amide hydrolase. WO2009138416 (2009).

[94] Apodaca, R., Breitenbucher, J.G., Pattabiraman, K., Seierstad, M., Xiao, W. Piperazinyl and piperidinyl ureas as modulators of fatty acid amide hydrolase. WO2006074025 (2006).

[95] Matsumoto, T., Kori, M., Miyazaki, J., Kiyota, Y. Preparation of piperidinecarboxamides and piperazinecarboxamides as fatty acid amide hydrolase (FAAH) inhibitors. WO2006054652 (2006).

[96] Fay, L.K., Johnson, D.S., Lazerwith, S.E., Morris, M.A., Wang, L.J., Meyers, M.J., Kesten, S.R., Stiff, C.M. Preparation of (hetero)biaryl ether methylidenepiperidinyl ureas as fatty acid amide hydrolase (FAAH) inhibitors. WO2008047229 (2008).

[97] Fay, L.K., Johnson, D.S., Meyers, M.J., Schweitzer, B.A., Thorarensen, A.,Wang, L.J. Ether benzylidene piperidine 5membered aryl carboxamide compounds as FAAH inhibitors and their preparation. WO2009127943 (2009). 
[98] Fay, L.K., Johnson, D.S., Meyers, M.J., Thorarensen, A.,Wang, L.J. Ether benzylidene piperidine aryl carboxamide compounds as FAAH inhibitors and their preparation. WO2009127944 (2009).

[99] Meyers, M.J., Pelc, M.J., Thorarensen, A., Schweitzer, B. A. 4-[3(Aryloxy)benzylidene]-3-methylpiperidine 5-membered aryl carboxamide compounds as FAAH inhibitors and their preparation. WO2009127948 (2009).

[100] Meyers, M.J., Pelc, M.J.,Thorarensen, A. 4-[3(Aryloxy)benzylidene]-3-methylpiperidine aryl carboxamide compounds useful as FAAH inhibitors and their preparation. WO2009127949 (2009).

[101] Long, S.A., Meyers, M.J., Pelc, M.J., Schweitzer, B.A., Thorarensen, A.,Wang, L.J. Preparation of 7-azaspiro[3.5]nonane7-carboxamides as inhibitors of fatty acid amide hydrolase (FAAH). WO2010049841 (2010).

[102] Long, S.A., Meyers, M.J., Pelc, M.J., Schweitzer, B.A., Thorarensen, A.,Wang, L.J. Preparation of 1-Oxa-8azaspiro[4,5]decane-8-carboxamide compounds as FAAH inhibitors for therapy. WO2010058318 (2010).

[103] Even, L., Hoornaert, C. Derivatives of triazolopyridine carboxamides, particularly (piperazin-1-yl)(1,2,3-triazolo[4,5b]pyridin-1-yl)methanones, their preparation and use as selective monoacyl glycerol lipase (MGL) inhibitors or mixed MGL and fatty acid amide hydrolase inhibitors. WO2008145843 (2008).

[104] Even, L., Hoornaert, C. Derivatives of triazolopyridine carboxamides, particularly (piperazin-1-yl)(1,2,3-triazolo[4,5b]pyridin-1-yl)methanones and (piperidin-1-yl)(1,2,3-triazolo[4,5b]pyridin-1-yl) methanones, their preparation and use as selective monoacyl glycerol lipase (MGL) inhibitors or mixed MGL and fatty acid amide hydrolase inhibitors. WO2008145839 (2008).

[105] Apodaca, R., Breitenbucher, J.G., Pattabiraman, K., Seierstad, M., Xiao, W. N-heteroarylpiperazinyl ureas as modulators of fatty acid amide hydrolase. WO2007005510 (2007).

[106] Apodaca, R., Breitenbucher, J. G., Hawryluk, N., A, , Jones, W., M,, Keith, J., M,, Merit, J., E, Tichenor, M., S,, Timmons, A., K Heteroaryl-substituted urea modulators of fatty acid amide hydrolase. WO2008153752 (2008)

[107] Breitenbucher, J. G., Keith, J. M., Tichenor, M. S., Chambers, A. L., Jones, W. M., Hawryluk, N. A., Timmons, A. K., Merit, J. E., Seierstad, M. J. Preparation of heteroaryl-substituted urea modulators of fatty acid amide hydrolase. WO2010068453 (2010)

[108] Hawryluk, N.A. Preparation of piperazinecarboxamide derivative as fatty acid amide hydrolase modulator. WO2011060026 (2011).

[109] Ishii, T., Sugane, T., Kakefuda, A., Takahashi, T., Kanayama, T., Sato, K., Kuriwaki, I., Kitada, C., Suzuki, J. Preparation of piperazine-1-carboxamide and piperidine-1-carboxamide derivatives as inhibitors of fatty acid amide hydrolase (FAAH). WO2008023720 (2008)

[110] Kori, M.M.K. amide compounds. US2009163508 (2009).

[111] Matsumoto, T., Kori, M., Kouno, M. Preparation of piperazine-1carboxamide derivatives as brain/neuronal cell-protecting agents, and therapeutic agents for sleep disorder. WO2007020888 (2007).

[112] Roughley, S., Walls, S., Hart, T., Parsons, R., Brough, P., Graham, C., Macias, A. Azetidine derivatives as inhibitors of fatty acid amide hydrolase useful in the treatment of diseases and preparation and pharmaceutical compositions thereof. WO2009109743 (2009).

[113] Breitenbucher, G.J., Tichenor, M.S., Merit, J.E., Hawryluk, N.A., Chambers, A. L., Keith, J.M. Preparation of aryl-substituted heterocyclic urea modulators of fatty acid amide hydrolase. WO2010141809 (2010)

[114] Breitenbucher, G.J., Keith, J. M., Jones, W.M. Preparation of heteroaryl-substituted spirocyclic diamine urea modulators of fatty acid amide hydrolase inhibitors. WO2010141817 (2010).

[115] Yang, W., Gao, X.,Wang, B. Boronic acid compounds as potential pharmaceutical agents. Med Res Rev 2003; 23(3): 346-68.

[116] Adams, J., Behnke, M.L., Castro, A.C., Evans, C.A., Grenier, L., Grogan, M.J., Liu, T., Snyder, D.A., Tibbitts, T.T. Preparation of arylboronates as inhibitors of fatty acid amide hydrolase. WO2008063300 (2008)

[117] Minkkila A, Saario SM, Ka sna nen H, Leppa nen J, Poso A, Nevalainen T. Discovery of boronic acids as novel and potent inhibitors of fatty acid amide hydrolase. J Med Chem 2008; 51(22): 7057-60.

[118] Behnke, M.L., Castro, A.C., Evans, C.A., Grenier, L., Grogan, M.J., Liu, T., Snyder, D.A., Tibbitts, T.T. Preparation of oxadiazolylphenylboronic acid derivatives and analogs for use as fatty acid amide hydrolase inhibitors. WO2009126691 (2009).

[119] Castro, A.C., Grogan, M.J.,Snyder, D.A. Inhibitors of fatty acid amide hydrolase. WO2010118155 (2010)

[120] Castro, A. C., Evans, C. A., Grenier, L.,Grogan, M. J. Preparation of piperidineboronic acid derivatives for use as fatty acid amide hydrolase inhibitors. WO2010118159 (2010)

[121] Bartolini, W., Cali, B.M., Chen, B., Chen, Y.-T., Currie, M.G., Milne, G.T., Pearson, J.P., Talley, J.J., Yang, J.J., Zimmerman, C. Preparation of indoleacetates as modulators of chemoattractant receptor homologous molecule expressed on Th2 cells (CRTH2), cyclooxygenase-2 (COX-2) and fatty acid amide hydrolase (FAAH). WO2006036994 (2006).

[122] Sprott, K., Talley, J.J., Pearson, J.P.,Milne, T.G. Indole derivatives as FAAH inhibitors and their preparation and use in the treatment of diseases. WO2008157740 (2008).

[123] Bartolini, W., Cali, B.M., Chen, B., Chien, Y.-T., Currie, M.G., Milne, G.T., Pearson, J.P., Talley, J.J., Yang, J.J., Zimmerman, C., Monreal, A.W. Preparation of indolylalkanoates as modulators of CRTH2, COX-1, COX-2, CD11B, TXA2, DAO, DP1, and/or FAAH. WO2007022501 (2007)

[124] Bartolini, W., Cali, B.M., Chen, B., Chien, Y.-T., Currie, M.G., Milne, G.T., Pearson, J.P., Talley, J.J., Zimmerman, C. Synthesis of COX-2 and FAAH inhibitors. WO2006050120 (2006).

[125] Sprott, K., Talley, J.J., Yang, J., Peng, B. Preparation of benzylpyrrolyloxoacetamide derivatives for use as FAAH inhibitors. WO2011071996 (2011).

[126] Learmonth, D.A., Kiss, L.E., Beliaev, A., Ferreira, H.D.S., Silva, P.M.V.A.S.D. 5-O-Substituted 3-N-phenyl-1,3,4-oxadiazolones as FAAH inhibitors and their preparation and use in the treatment of diseases. WO2009084970 (2009).

[127] Learmonth, D.A., Da Silva, P.M.V.A.S. 5-O-Substituted 3-N-aryl1,3,4-oxadiazolone derivatives as FAAH inhibitors and their preparation and use for the treatment of diseases. WO2010074587 (2010)

[128] Learmonth, D.A., Da Silva, P.M.V.A.S., Kiss, L.E. Preparation of $\mathrm{N}$-heteroaryloxadiazolone derivatives for use as FAAH inhibitors. WO2010151160 (2010).

[129] Lin, L.S., Chioda, M. D., Liu, P., Nargund, R.P. Preparation of imidazole derivatives useful as inhibitors of FAAH. WO2009152025 (2009).

[130] Liu, P., Devita, R.J., Lin, L.S., Chioda, M.D., Hamill, T.G., Li, W. Imidazole derivatives useful as modulators of FAAH and as FAAH imaging agents WO2010101724 (2010).

[131] Lin, L.S., Chang, L.L., Chobanian, H., Nargund, R.P. Pyrazole derivatives useful as inhibitors of FAAH. WO2009151991 (2009).

[132] Chobanian, H., Lin, L. S., Liu, P., Chioda, M. D., Devita, R. J., Nargund, R. P., Guo, Y. Preparation of oxazole derivatives as inhibitors of FAAH. WO2010017079 (2010).

[133] Kelly, M.G., Kincaid, J., Gowlugari, S., Kaub, C. Preparation of substituted naphthyridines as FAAH modulators. WO2009011904 (2009).

[134] Kaub, C., Gowlugari, S., Kincaid, J., Johnson, R.J., O'Mahony, D.J.R., Estiarte-Martinez, M.d.L.A., Duncton, M. Preparation of benzoxazole compounds as FAAH modulators. WO2010039186 (2010).

[135] Duncton, M., O'Mahony, D.J.R.,Cox, M. 6,7-Dihydro-5Hpyrrolo[3,4-d]pyrimidin-4-yl(quinolin-3-yl)amine derivatives as FAAH modulators and their preparation and use for the treatment of diseases. WO2010059610 (2010).

[136] Apodaca, R., Breitenbucher, J.G., Chambers, A.L., Deng, X., Hawryluk, N.A., Keith, J.M., Mani, N.S., Merit, J.E., Pierce, J.M., Seierstad, M., Xiao, W. Preparation of aryl-hydroxyethylaminopyrimidines and triazines as modulators of fatty acid amide hydrolase. WO2009105220 (2009).

[137] Hawryluk, N.A., Breitenbucher, J.G., Jones, W.M., Chambers, A.L., Keith, J. M., Seierstad, M. Preparation of pyrimidinyl ethylene diamine derivatives as modulators of fatty acid amide hydrolase. WO2011022348 (2011).

[138] Behnke, M.L., Castro, A.C., Chan, L.K., Evans, C.A., Grenier, L., Grogan, M.J., Leblanc, Y., Liu, T., Peluso, S., Snyder, D.A., Tibbitts, T.T. Preparation of isoxazoline derivatives for use as fatty acid amide hydrolase inhibitors. WO2010135360 (2010).

[139] Behnke, M.L., Castro, A.C., Chan, L.K., Evans, C.A., Grenier, L., Grogan, M.J., Leblanc, Y., Liu, T., Peluso, S., Snyder, D.A., 
Tibbitts, T.T. Isoxazolines as inhibitors of fatty acid amide hydrolase US2011028478 (2011).

[140] Behnke, M.L., Castro, A.C., Chan, L.K., Evans, C.A., Grenier, L., Grogan, M.J., Leblanc, Y., Liu, T., Peluso, S., Snyder, D.A., Tibbitts, T.T. Isoxazolines as inhibitors of fatty acid amide hydrolase. US2011034437 (2011).

[141] Muccioli GG, Fazio N, Scriba GKE, Poppitz W, Cannata F, Poupaert JH, et al. Substituted 2-thioxoimidazolidin-4-ones and imidazolidine-2,4-diones as fatty acid amide hydrolase inhibitors templates. J Med Chem 2006; 49(1): 417-25.

[142] Wang X, Sarris K, Kage K, Zhang D, Brown SP, Kolasa T, et al. Synthesis and evaluation of benzothiazole-based analogues as novel, potent, and selective fatty acid amide hydrolase inhibitors. J Med Chem 2008; 52(1): 170-80.

[143] Onnis V, Congiu C, Bjo rklund E, Hempel F, So derstro m E, Fowler CJ. Synthesis and evaluation of paracetamol esters as novel fatty acid amide hydrolase inhibitors. J Med Chem 2010; 53(5): 2286-98.

[144] De Wael F, Muccioli GG, Lambert DM, Sergent T, Schneider Y-J, Rees J-F, et al. Chemistry around imidazopyrazine and ibuprofen: Discovery of novel fatty acid amide hydrolase (FAAH) inhibitors. Eur J Med Chem 2010; 45(9): 3564-74.

[145] Forster L, Ludwig J, Kaptur M, Bovens S, Elfringhoff AS, Holtfrerich A, et al. 1-Indol-1-yl-propan-2-ones and related heterocyclic compounds as dual inhibitors of cytosolic phospholipase A2[alpha] and fatty acid amide hydrolase. Bioorg Med Chem 2010; 18(2): 945-52.

[146] Feledziak M, Muccioli GG, Lambert DM, Marchand-Brynaert J. SAR and LC/MS studies of $\beta$-lactamic inhibitors of human fatty acid amide hydrolase (hFAAH): Evidence of a Nonhydrolytic Process. J Med Chem 2011; 54(19): 6812-23.

[147] Min X, Thibault ST, Porter AC, Gustin DJ, Carlson TJ, Xu H, et al. Discovery and molecular basis of potent noncovalent inhibitors of fatty acid amide hydrolase (FAAH). Proc. Natl. Acad. Sci. 2011; 108(18): 7379-84.

[148] Tornqvist H, Belfrage P. Purification and some properties of a monoacylglycerol-hydrolyzing enzyme of rat adipose tissue. J Biol Chem 1976; 251(3): 813-9.

[149] Kupiecki FP. Partial purification of monoglyceride lipase from adipose tissue. J Lipid Res 1966; 7(2): 230-5.

[150] Karlsson M, Contreras JA, Hellman U, Tornqvist H, Holm C. cDNA cloning, tissue distribution, and identification of the catalytic triad of monoglyceride lipase. J Biol Chem 1997; 272(43): 27218-23.

[151] Saario SM. Characterization of the sulfhydryl-sensitive site in the enzyme responsible for hydrolysis of 2-arachidonoyl-glycerol in rat cerebellar membranes. Chem Biol 2005; 12: 649-56.

[152] Zvonok N, Pandarinathan L, Williams J, Johnston M, Karageorgos I, Janero DR, et al. Covalent inhibitors of human monoacylglycerol lipase: ligand-assisted characterization of the catalytic site by mass spectrometry and mutational analysis. Chem Biol 2008; 15(8): 85462.

[153] King AR, Lodola A, Carmi C, Fu J, Mor M, Piomelli D. A critical cysteine residue in monoacylglycerol lipase is targeted by a new class of isothiazolinone-based enzyme inhibitors. Br J Pharmacol 2009; 157(6): 974-83.

[154] Kapanda CN, Muccioli GG, Labar G, Poupaert JH, Lambert DM. Bis(dialkylaminethiocarbonyl)disulfides as Potent and Selective Monoglyceride Lipase Inhibitors. J Med Chem 2009; 52(22): 73104.

[155] Labar G, Bauvois C, Borel F, Ferrer J-L, Wouters J, Lambert DM. Crystal structure of the human monoacylglycerol lipase, a key actor in endocannabinoid signaling. Chem Bio Chem 2010; 11(2): 218227.

[156] Bertrand T, Augé F, Houtmann J, Rak A, Vallée F, Mikol V, et al. Structural basis for human monoglyceride lipase inhibition. J Mol Biol 2010; 396(3): 663-73.

[157] Sugiura T, Kishimoto S, Oka S, Gokoh M. Biochemistry, pharmacology and physiology of 2-arachidonoylglycerol, an endogenous cannabinoid receptor ligand. Prog Lipid Res 2006; 45(5): 405-46.

[158] Panikashvili D, Simeonidou C, Ben-Shabat S, Hanus L, Breuer A, Mechoulam R, et al. An endogenous cannabinoid (2-AG) is neuroprotective after brain injury. Nature 2001; 413(6855): 527531 .
[159] Panikashvili D, Shein NAA, Mechoulam R, Trembovler V, Kohen $\mathrm{R}$, Alexandrovich A, et al. The endocannabinoid 2-AG protects the blood-brain barrier after closed head injury and inhibits mRNA expression of proinflammatory cytokines. Neurobiol Dis 2006; 22(2): 257-64.

[160] Zhang J, Chen C. Endocannabinoid 2-arachidonoylglycerol protects neurons by limiting COX-2 elevation. J Biol Chem 2008; 283(33): 22601-11.

[161] Kirkham TC, Williams CM, Fezza F, Di Marzo V. Endocannabinoid levels in rat limbic forebrain and hypothalamus in relation to fasting, feeding and satiation: stimulation of eating by 2-arachidonoyl glycerol. Br J Pharmacol 2002; 136(4): 550-7.

[162] Tuboly G, Mecs L, Benedek G, Horvath G. Antinociceptive interactions between anandamide and endomorphin-1 at the spinal level. Clin Exp Pharmacol Physiol 2009; 36: 400-5.

[163] Guindon J, Hohmann AG, The endocannabinoid system and cancer: therapeutic implication. $\mathrm{Br} \mathrm{J}$ Pharmacol 2011; 163(7): 1447-63.

[164] Nomura DK, Long JZ, Niessen S, Hoover HS, Ng S-W,Cravatt BF. Monoacylglycerol lipase regulates a fatty acid network that promotes cancer pathogenesis. Cell 2010; 140(1): 49-61.

[165] Bisogno T, Ortar G, Petrosino S, Morera E, Palazzo E, Nalli M, et al. Development of a potent inhibitor of 2-arachidonoylglycerol hydrolysis with antinociceptive activity in vivo. Biochim Biophys Acta 2009; 1791(1): 53-60.

[166] Comelli F, Giagnoni G, Bettoni I, Colleoni M, Costa B. The inhibition of monoacylglycerol lipase by URB602 showed an antiinflammatory and anti-nociceptive effect in a murine model of acute inflammation. Br J Pharmacol 2007; 152(5): 787-94.

[167] Kinsey SG, Nomura DK, O'Neal ST, Long JZ, Mahadevan A, Cravatt $\mathrm{BF}$, et al. Inhibition of monoacylglycerol lipase attenuates nonsteroidal anti-inflammatory drug-induced gastric hemorrhages in mice. J Pharmacol Exp Ther 2011;338(3):795-802

[168] Alhouayek M, Lambert DM, Delzenne NM, Cani PD, Muccioli GG. Increasing endogenous 2-arachidonoylglycerol levels counteracts colitis and related systemic inflammation. FASEB J 2011.

[169] Sticht MA, Long JZ, Rock EM, Limebeer CL, Mechoulam R, Cravatt BF, et al. The MAGL inhibitor, JZL184, attenuates LiClinduced vomiting in the Suncus murinus and $2 \mathrm{AG}$ attenuates $\mathrm{LiCl}-$ induced nausea-like behavior in rats. Br J Pharmacol 2011: no-no.

[170] Labar G, Wouters J, Lambert DM. A review on the monoacylglycerol lipase: at the interface between fat and endocannabinoid signalling. Curr Med Chem 2010; 17(24): 2588607.

[171] Hoornaert C. Triazolopyridine carboxamide derivatives, preparation thereof and therapeutic use thereof. WO2008145842 (2008).

[172] Makriyannis, A., Pandarinathan, L., Zvonok, N., Parkkari, T.,Chapman, L. Inhibitors of fatty acid amide hydrolase and monoacylglycerol lipase for modulation of cannabinoid receptors. WO2009117444 (2009).

[173] Hohmann AG, Suplita RL, Bolton NM, Neely MH, Fegley D, Mangieri $\mathrm{R}$, et al. An endocannabinoid mechanism for stressinduced analgesia. Nature 2005; 435: 1108-12.

[174] Vandevoorde S, Jonsson KO, Labar G, Persson E, Lambert DM, Fowler CJ. Lack of selectivity of URB602 for 2-oleoylglycerol compared to anandamide hydrolysis in vitro. Br J Pharmacol 2007; 150: 186-91.

[175] Saario SM, Palomäki V, Lehtonen M, Nevalainen T, Järvinen T, Laitinen JT. URB754 has no effect on the hydrolysis or signaling capacity of 2-AG in the rat brain. Chem Biol 2006; 13(8): 811-4.

[176] Long JZ, Jin X, Adibekian A, Li W, Cravatt BF. Characterization of tunable piperidine and piperazine carbamates as inhibitors of endocannabinoid hydrolases. J Med Chem 2010; 53(4): 1830-42.

[177] Cravatt, B.F., Long, J.Z., Li, W., Nomura, D.K. Methods and compositions related to targeting monoacylglycerol lipase. WO2010056309 (2010).

[178] Long JZ, Li W, Booker L, Burston JJ, Kinsey SG, Schlosburg JE, et al. Selective blockade of 2-arachidonoylglycerol hydrolysis produces cannabinoid behavioral effects. Nat Chem Biol 2009; 5(1): 37-44.

[179] Makriyannis, A., Nikas, S.P., Alapafuja, S.O., Shukla, V.G. Sulfonyl fluorides, trifluoromethyl ketones, carbamates, $\alpha$-ketooxadiazoles and saccharin analogues as monoacylglycerol lipase inhibitors for modulation of cannabinoid activity and their 
preparations, pharmaceutical compositions and use in the treatment of diseases. WO2009052319 (2009)

[180] Bian, H., Chevalier, K.M., Connolly, P.J., Flores, C.M., Lin, S.-C., Liu, L., Mabus, J., Macielag, M.J., Mcdonnell, M.E., Pitis, P.M., Zhang, Y.-M., Zhang, S.-P., Clemente, J., Zhu, B. Azetidinyl diamides as monoacylglycerol lipase inhibitors. WO2010124114 (2010).

[181] Chevalier, K.M., Dax, S.L., Flores, C.M., Liu, L., Macielag, M.J., Mcdonnell, M.E., Nelen, M.I., Prouty, S., Todd, M., Zhang, S.-P., Zhu, B., Nulton, E.L., Clemente, J. Heteroaromatic and aromatic piperazinyl azetidinyl amides as monoacylglycerol lipase inhibitors WO2010124121 (2010)

[182] Flores, C.M., Nelen, M.I., Nulton, E.L., Prouty, S., Todd, M., Zhang, S.-P. Heteroaromatic and aromatic piperazinyl azetidinyl amides as monoacylglycerol lipase inhibitors WO2010124122 (2010).

[183] Schubert, C., Grasberger, B.L., Schalk-Hihi, C., Maguire, D.M., Lewandowski, F.A., Milligan, C.M., Alexander, R.S. Crystal structure and alternative crystal form of human monoacylglycerol lipase (MGLL), and use for design and screening of MGLL inhibitors. WO2009132267 (2010).

[184] Schalk-Hihi C, Schubert C, Alexander R, Bayoumy S, Clemente JC, Deckman I, et al. Crystal structure of a soluble form of human monoglyceride lipase in complex with an inhibitor at $1.35 \AA$ resolution. Protein Sci 2011; 20(4): 670-83.

[185] Muccioli GG, Labar G, Lambert DM. CAY10499, a novel monoglyceride lipase inhibitor evidenced by an expeditious MGL assay. ChemBioChem 2008; 9(16): 2704-10.

[186] Minkkilä A, Savinainen JR, Käsnänen H, Xhaard H, Nevalainen T, Laitinen JT, et al. Screening of various hormone-sensitive lipase inhibitors as endocannabinoid-hydrolyzing enzyme inhibitors. Chem Med Chem 2009; 4(8): 1253-9.

[187] Tsuboi K, Takezaki N, Ueda N. The N-acylethanolaminehydrolyzing acid amidase (NAAA). Chem Biodivers 2007; 4(8): 1914-25.

[188] Ueda N, Yamanaka K, Yamamoto S. Purification and characterization of an acid amidase selective for $\mathrm{N}$ palmitoylethanolamine, a putative endogenous anti-inflammatory substance. J Biol Chem 2001; 276(38): 35552-7.

[189] Tsuboi K, Sun Y-X, Okamoto Y, Araki N, Tonai T,Ueda N. Molecular characterization of N-Acylethanolamine-hydrolyzing acid amidase, a novel member of the choloylglycine hydrolase family with structural and functional similarity to acid ceramidase. J Biol Chem 2005; 280(12): 11082-92.

[190] Tsuboi K, Zhao L-Y, Okamoto Y, Araki N, Ueno M, Sakamoto H, et al. Predominant expression of lysosomal N-acylethanolaminehydrolyzing acid amidase in macrophages revealed by immunochemical studies. Biochim Biophys Acta 2007; 1771(5): 623-32.

[191] Tsuboi K, Takezaki N, Ueda N. The N-AcylethanolamineHydrolyzing Acid Amidase (NAAA). Chemistry \& Biodiversity 2007; 4(8): 1914-25.

[192] Oinonen C, Rouvinen J. Structural comparison of Ntn-hydrolases. Protein Sci 2000; 9(12): 2329-37.

[193] Wang J, Zhao L-Y, Uyama T, Tsuboi K, Tonai T,Ueda N. Amino acid residues crucial in $\mathrm{pH}$ regulation and proteolytic activation of $\mathrm{N}$-acylethanolamine-hydrolyzing acid amidase. Biochim Biophys Acta 2008; 1781(11-12): 710-7.

[194] Fegley, D. Characterization of the fatty acid amide hydrolase inhibitor cyclohexyl carbamic acid 3[prime]-carbamoyl-biphenyl3-yl ester (URB597): effects on anandamide and oleoylethanolamide deactivation. J Pharmacol Exp Ther 2005; 313: 352-8.

[195] Mazzari S, Canella R, Petrelli L, Marcolongo G, Leon A, N-(2Hydroxyethyl)hexadecanamide is orally active in reducing edema formation and inflammatory hyperalgesia by down-modulating mast cell activation. Eur J Pharmacol. 1996; 300(3): 227-36.

[196] Lambert DM, Vandevoorde S, Diependaele G, Govaerts SJ, Robert AR. Anticonvulsant activity of N-palmitoylethanolamide, a putative endocannabinoid, in mice. Epilepsia 2001; 42(3): 321-7.

[197] Lo Verme J, Fu J, Astarita G, La Rana G, Russo R, Calignano A, et al. The nuclear receptor peroxisome proliferator-activated receptor- $\alpha$ mediates the anti-inflammatory actions of palmitoylethanolamide. Mol Pharmacol 2005; 67(1): 15-9.

[198] Vandevoorde S, Jonsson KO, Fowler CJ, Lambert DM. Modifications of the ethanolamine head in N-palmitoylethanolamine: synthesis and evaluation of new agents interfering with the metabolism of anandamide. J Med Chem 2003; 46(8): 1440-8.

[199] Vandevoorde S, Tsuboi K, Ueda N, Jonsson K-O, Fowler CJ, Lambert DM. Esters, retroesters, and a retroamide of palmitic acid: pool for the first selective inhibitors of n-palmitoylethanolamineselective acid amidase. J Med Chem 2003; 46(21): 4373-6.

[200] Tsuboi K, Hilligsmann C, Vandevoorde S, Lambert DM, Ueda N. $\mathrm{N}$-cyclohexanecarbonylpentadecylamine: a selective inhibitor of the acid amidase hydrolysing $\mathrm{N}$-acylethanolamines, as a tool to distinguish acid amidase from fatty acid amide hydrolase. Biochem J 2004; 379(1): 99-106.

[201] Saturnino C, Petrosino S, Ligresti A, Palladino C, Martino GD, Bisogno $\mathrm{T}$, et al. Synthesis and biological evaluation of new potential inhibitors of $\mathrm{N}$-acylethanolamine hydrolyzing acid amidase. Bioorg Med Chem Lett 2010; 20(3): 1210-3

[202] Piomelli, D., Tarzia, G., Mor, M., Duranti, A.,Tontini, A. Preparation of oxooxetanes and related compounds as NAAA (Nacylethanolamine-hydrolyzing acid amidase) inhibitors. WO2009049238 (2009).

[203] Solorzano C, Zhu C, Battista N, Astarita G, Lodola A, Rivara S, et al. Selective N-acylethanolamine-hydrolyzing acid amidase inhibition reveals a key role for endogenous palmitoylethanolamide in inflammation. Proc Natl Acad Sci 2009; 106(49): 20966-71.

[204] Solorzano C, Antonietti F, Duranti A, Tontini A, Rivara S, Lodola A, et al. Synthesis and structure-activity relationships of N-(2-Oxo3-oxetanyl) amides as N-Acylethanolamine-hydrolyzing Acid Amidase Inhibitors. J Med Chem 2010; 53(15): 5770-81.

[205] Long JZ, Nomura DK,Cravatt BF. Characterization of monoacylglycerol lipase inhibition reveals differences in central and peripheral endocannabinoid metabolism. Chem Biol 2009; 16(7): 744-53.

[206] Long JZ, LaCava M, Jin X, Cravatt BF. An anatomical and temporal portrait of physiological substrates for fatty acid amide hydrolase. J Lipid Res 2011; 52(2): 337-44.

[207] Chanda PK, Gao Y, Mark L, Btesh J, Strassle BW, Lu P, et al. A., Monoacylglycerol Lipase Activity Is a Critical Modulator of the Tone and Integrity of the Endocannabinoid System. Mol Pharmacol 2010; 78(6): 996-1003.

[208] Schlosburg JE, Blankman JL, Long JZ, Nomura DK, Pan B, Kinsey SG, et al. Chronic monoacylglycerol lipase blockade causes functional antagonism of the endocannabinoid system. Nat Neurosci 2010; 13(9): 1113-19.

[209] Nomura DK, Morrison BE, Blankman JL, Long JZ, Kinsey SG, Marcondes MC, et al. Endocannabinoid hydrolysis generates brain prostaglandins that promote neuroinflammation. Sci 2011; In Press (DOI 10.1126/science.1209200).

[210] Li W, Blankman JL, Cravatt BF. A functional proteomic strategy to discover inhibitors for uncharacterized hydrolases. J Am Chem Soc 2007; 129: 9594-5.

[211] Bachovchin DA, Ji T, Li W, Simon GM, Blankman JL, Adibekian A, et al. Superfamily-wide portrait of serine hydrolase inhibition achieved by library-versus-library screening. Proc Natl Acad Sci 2010; 107(49): 20941-6.

[212] Marrs WR, Horne EA, Ortega-Gutierrez S, Cisneros JA, Xu C, Lin $\mathrm{YH}$, et al. Dual inhibition of $\alpha / \beta$-hydrolase domain 6 and fatty acid amide hydrolase increases endocannabinoid levels in neurons. $\mathbf{J}$ Biol Chem 2011; 286(33): 28723-8.

[213] Xie S, Borazjani A, Hatfield MJ, Edwards CC, Potter PM, Ross MK. Inactivation of lipid glyceryl ester metabolism in human THP1 monocytes/macrophages by activated organophosphorus insecticides: role of carboxylesterases 1 and 2. Chem Res Toxicol 2010; 23(12): 1890-904.

[214] Sun Y-X, Tsuboi K, Zhao L-Y, Okamoto Y, Lambert DM, Ueda N. Involvement of $\mathrm{N}$-acylethanolamine-hydrolyzing acid amidase in the degradation of anandamide and other $\mathrm{N}$-acylethanolamines in macrophages. Biochim Biophys Acta 2005; 1736(3): 211-20. 